\title{
Polyaromatic disordered carbon grains as carriers of the UV bump: Far-UV to mid-IR spectroscopy of laboratory analogs
}

\author{
L. Gavilan ${ }^{1,2}$, K. C. Le ${ }^{3}$, T. Pino ${ }^{3}$, I. Alata ${ }^{2,3}$, A. Giuliani ${ }^{4,5}$, and E. Dartois ${ }^{2}$ \\ ${ }^{1}$ Université Versailles St-Quentin; Sorbonne Universités, UPMC Université Paris 06, CNRS/INSU, LATMOS-IPSL, \\ 78280 Guyancourt, France \\ e-mail: lissethgavilan@gmail.com; lisseth.gavilan@latmos.ipsl.fr \\ 2 Institut d'Astrophysique Spatiale (IAS), CNRS, Université Paris Sud, Université Paris-Saclay, 91405 Orsay, France \\ ${ }^{3}$ Institut des Sciences Moléculaires d'Orsay (ISMO), CNRS, Univ. Paris Sud, Université Paris-Saclay, 91405 Orsay, France \\ ${ }^{4}$ DISCO beam line, SOLEIL synchrotron, Saint Aubin, BP 48, 91192 Gif-sur-Yvette, France \\ 5 INRA, UAR1008 CEPIA, 44316 Nantes, France
}

Received 28 February 2017 / Accepted 24 July 2017

\begin{abstract}
Context. A multiwavelength study of laboratory carbons with varying degrees of hydrogenation and $\mathrm{sp}^{2}$ hybridization is required to characterize the structure of the carbonaceous carriers of interstellar and circumstellar extinction.

Aims. We study the spectral properties of carbonaceous dust analogs from the far-ultraviolet to the mid-infrared and correlate features in both spectral ranges to the aromatic/aliphatic degree.

Methods. Analogs to carbonaceous interstellar dust encountered in various phases of the interstellar medium have been prepared in the laboratory. These are amorphous hydrogenated carbons $(\mathrm{a}-\mathrm{C}: \mathrm{H})$, analogs to the diffuse interstellar medium component, and soot particles, analogs to the polyaromatic component. Thin films $(d<100 \mathrm{~nm})$ have been measured in transmission in the vacuumultraviolet (VUV; 120-210 nm) within the atmospheric pressure experiment (APEX) chamber of the DISCO beam line at the SOLEIL synchrotron radiation facility. Spectra of these films were further measured through the UV-Vis $(210 \mathrm{~nm}-1 \mu \mathrm{m})$ and in the mid-infrared (3-15 $\mu \mathrm{m})$.

Results. Tauc optical gaps, $E_{\mathrm{g}}$, are derived from the visible spectra. The major spectral features are fitted through the VUV to the midinfrared to obtain positions, full-widths at half maximum (FWHM), and integrated intensities. These are plotted against the position of the $\pi-\pi^{*}$ electronic transitions peak. Unidentified or overlapping features in the UV are identified by correlations with complementary infrared data. A correlation between the optical gap and position of the $\pi-\pi^{*}$ electronic transitions peak is found. The latter is also correlated to the position of the $\mathrm{sp}^{3}$ carbon defect band at $\sim 8 \mu \mathrm{m}$, the aromatic $\mathrm{C}=\mathrm{C}$ stretching mode position at $\sim 6 \mu \mathrm{m}$, and the $\mathrm{H} / \mathrm{C}$ ratio.

Conclusions. Ultraviolet and infrared spectroscopy of structurally diverse carbon samples are used to constrain the nanostructural properties of carbon carriers of both circumstellar and interstellar extinction, such as the associated coherent lengths and the size of polyaromatic units. Our study suggests that carriers of the interstellar UV bump should exhibit infrared bands akin to the $\mathrm{A} / \mathrm{B}$ classes of the aromatic infrared bands, while the circumstellar bump carriers should exhibit bands corresponding to the $\mathrm{B} / \mathrm{C}$ classes.
\end{abstract}

Key words. dust, extinction - infrared: ISM - galaxies: ISM - methods: laboratory: solid state - ultraviolet: ISM

\section{Introduction}

The diversity of carbonaceous solids in interstellar and circumstellar environments in our Galaxy and in extra-galactic lines of sight has been the subject of numerous theoretical, observational, and experimental studies (Draine \& Lee 1984; Greenberg \& Li 1999; Pendleton \& Allamandola 2002; Dartois et al. 2005; Pino et al. 2008; Godard \& Dartois 2010; Duley \& Hu 2012; Jones 2012a-c). Observations of interstellar extinction were first documented by Trumpler (1930). One prominent spectral feature in extinction curves in the Milky Way is a broad ultraviolet absorption bump consistently centered at $217.5 \mathrm{~nm}\left(4.6 \mu \mathrm{m}^{-1}\right)$. The UV bump was first observed in the 1960s by Stecher \& Donn (1965), but its carrier is still not fully understood, although it has been generally attributed to electronic transitions in carbon. Fitzpatrick \& Massa (1986) first parametrized the UV bump using data from the International Ultraviolet Explorer (IUE) toward 45 reddened OB Milky
Way stars. They found that the position of the bump was mildly variable while its full width at half maximum strongly variable; the lack of correlation between these parameters suggested that graphite was an improbable carrier. In Fitzpatrick \& Massa (1988) they included the far ultraviolet (FUV) extinction, finding that a Lorentzian (for the UV bump), a FUV rise, and an underlying linear continuum were necessary components. This study was expanded to 78 stars, published as an atlas (Fitzpatrick \& Massa 1990), and further extended to include 329 stars (Fitzpatrick \& Massa 2005, 2007). In the latter, stellar atmosphere models were used to eliminate spectral mismatch errors in the curves, and showed that extinction parameters are highly sensitive to local conditions. The exact origin and variability of interstellar extinction and the nature of the dust carriers across different wavelength ranges is still a central question in cosmic dust research.

Astronomical observations in the infrared also play an important role in dust characterization. Unidentified infrared 
emission bands (UIBs), also known as aromatic infrared bands (AIBs), are features between 3 and $20 \mu \mathrm{m}$ (3.3, 6.2, 7.7, 8.6, and $11.2 \mu \mathrm{m}$ ) widely observed in a range of environments in our Galaxy (e.g., Rosenberg et al. 2014; Peeters 2014). These bands are attributed to the infrared fluorescence of polyaromatic carriers, associated to the polycyclic aromatic hydrocarbon (PAH) hypothesis (Leger \& Puget 1984; Puget et al. 1985; Allamandola et al. 1985; Puget \& Leger 1989; Allamandola et al. 1989). However, alternative carriers have also been proposed, such as amorphous organic solids with mixed aromaticaliphatic structures due to mixed $\mathrm{sp}^{2}$ and $\mathrm{sp}^{3}$ hybridizations. Observations of a single carbon star with a circumstellar disk by Sloan et al. (2007) concluded that its spectra was consistent with hydrocarbon mixtures containing both aromatic and aliphatic bonds. Acke et al. (2010) suggested that a strong UV flux reduces the aliphatic component and emphasizes the spectral signature of the aromatics in the emission spectra towards Herbig Ae stars. Yang et al. (2013) studied the ratio of the $\mathrm{CH}$ stretching modes at 3.3 and $3.4 \mu \mathrm{m}$ in emission towards UIBs, and argued that their observed emitters are predominantly aromatic nanoparticles.

The spectroscopy of laboratory analogs to interstellar carbon dust has helped to unveil the origin of the UV bump. Draine \& Lee (1984) proposed early on that crystalline graphite could fit the UV bump, and later on Jones (1990) argued that hydrogenated amorphous carbons $(\mathrm{a}-\mathrm{C}: \mathrm{H})$ containing small polyaromatic units may be suitable carriers. Observations of the aliphatic bands at 6.85 and $7.25 \mu \mathrm{m}$ in absorption later revealed the presence of interstellar hydrogenated amorphous carbons (Pendleton \& Allamandola 2002; Dartois et al. 2004). Laboratory hydrogenated carbons have since then been considered realistic carriers of the bump (Colangeli et al. 1997; Schnaiter et al. 1998; Furton et al. 1999; Dartois et al. 2004). Laboratory a-C:Hs at different degrees of hydrogenation have been compared to observed astronomical spectra (Dartois et al. 2007; Duley \& Hu 2012). Soot nanoparticles prepared via laser pyrolisis (Jäger et al. 2006, 2008) are also candidates but only following the activation of $\pi-\pi^{*}$ transitions by UV irradiation (Gadallah et al. 2011). Indeed, energetic thermal and nonthermal processes can alter carbonaceous dust in the diffuse interstellar medium (ISM). In photo-dissociation regions, photodesorption processes compete with hydrogenation to effectively alter their structure and optical properties. This has been experimentally explored via UV irradiation of thin a-C:H films (Scott \& Duley 1996; Mennella et al. 1996, 2002; Alata et al. 2014, 2015), as well as via ion irradiation (Mennella et al. 2003; Godard et al. 2011). Recent optical models of interstellar dust (Jones 2012a-c; Jones et al. 2013) have shown that amorphous carbons extending over a wide range of optical gap energies can be used to fit the observed extinction from the FUV to the infrared. Russo et al. (2014) performed a UV study extending from 190 to $1100 \mathrm{~nm}$ on molecular-weight-sorted species prepared by combustion. Bescond et al. (2016) recently studied the optical properties of soots in the visible near-UV from 200-1100 nm and performed an inversion model to extract the size distribution and fractal dimension of soots. Few laboratory spectroscopic studies on carbonaceous dust extending over a wide spectral range exist, due to experimental difficulties in accessing the vacuum-ultraviolet (VUV). In this range, different techniques have been used including electron energy loss spectroscopy (EELS; Fink et al. 1984; Zubko et al. 1996) and synchrotron VUV sources (Colangeli et al. 1993; Gavilan et al. 2016).
For this study, we produced in the laboratory carbonaceous solids of mixed aromatic and aliphatic structures at different degrees of hydrogenation. By measuring them over a large spectral range (from the mid-infrared to the VUV), we expect to unveil relations between vibrational modes and electronic transitions, both observable signatures of interstellar dust, extending our previous findings in Gavilan et al. (2016). We aim to constrain the carbonaceous carriers of the interstellar UV bump and the circumstellar (CSM) UV bump and shed light on the spectroscopic decomposition of UV extinction based on our laboratory data. For the ISM, our work will be compared to the parameters of the interstellar $217.5 \mathrm{~nm}$ UV bump (Fitzpatrick \& Massa 2005, 2007). For the CSM, our work will be compared against the very few UV observations of circumstellar envelopes, in this case of H-poor post-asymptotic giant branch (AGB) and (hot) R Cor Borealis stars (Drilling et al. 1997; Blanco et al. 1995; Waelkens et al. 1995). Although this CSM is not representative of H-rich carbon stars, which provide most of the galactic carbonaceous dust, we use these UV observations as a first constraint to the circumstellar UV bump.

This article is organized as follows. In Sect. 2 we describe the experimental setups and sample preparation. In Sect. 3 we present the analysis of UV and IR bands. In Sect. 4 we discuss our analysis and astronomical implications, and in Sect. 5 we present our conclusions.

\section{Experiments}

The experimental setups used to prepare the carbonaceous samples have already been described in Gavilan et al. (2016). Here we provide further details relevant to the samples used in this study. Thin carbon films $(d<100 \mathrm{~nm})$ deposited on $\mathrm{MgF}_{2}$ windows were used for measurements between $120-1000 \mathrm{~nm}$, and thicker carbon films $(d>300 \mathrm{~nm})$ deposited on IR transparent $\mathrm{KBr}, \mathrm{CsI}$, and $\mathrm{KCl}$ windows for measurements in the midinfrared.

SICAL-ICP, a low pressure $\left(\sim 10^{-2}\right.$ mbar $)$ radiofrequency (R.F.) plasma reactor was used to prepare the hydrogenated amorphous carbon samples. A $13.56 \mathrm{MHz}$ R.F. power is inductively coupled to the plasma by impedance matching via a copper coil surrounding a glass cylinder (e.g., Dworschak 1990). While the a-C:H sample presented in Gavilan et al. (2016) was prepared using methane $\left(\mathrm{CH}_{4}\right)$ as the precursor gas, and an R.F. input power of $100 \mathrm{~W}$, the a-C:H presented in this paper was prepared using a plasma fed by toluene $\left(\mathrm{C}_{7} \mathrm{H}_{8}\right)$, and an R.F. input power of $150 \mathrm{~W}$. Our goal in this study was to produce a more aromatic a-C:H. The higher R.F. power (150 versus $100 \mathrm{~W}$ ) has an important influence on the structure of the produced solid hydrocarbon. Higher ion energies lead to preferential sputtering of hydrogen due to the lower binding energies of $\mathrm{CH}$ with respect to $\mathrm{CC}$ bonds.

We used the Nanograins combustion flame setup to produce soot nanoparticle films (Carpentier et al. 2012; Pino et al. 2015). In premixed flames, sooting is the result of competition between the rate of pyrolysis, growth of soot precursors, and oxidation rate (Mansurov 2005). The formation of soot nanoparticles can be described by the following equation,

$\mathrm{C}_{m} \mathrm{H}_{n}+\alpha \mathrm{O}_{2} \rightarrow 2 \alpha \mathrm{CO}+\frac{n}{2} \mathrm{H}_{2}+(m-2 \alpha) \mathrm{C}_{s}$,

where $m$ and $n$ are positive integers related to the hydrocarbon gas precursor type, $s$ is a positive integer related to the number of carbon atoms in a solid soot nanoparticle, and $\alpha$ is a positive rational for the oxidation coefficient. Theoretically, for soots to 
form in an ethylene flame, Eq. (1) imposes $\mathrm{C} / \mathrm{O}>1$. In practice, the sooting regime appears as soon as $\mathrm{C} / \mathrm{O} \sim 0.7$ at 40 mbar. Soots produced in an ethylene $\left(\mathrm{C}_{2} \mathrm{H}_{4}\right)$ flame, first introduced in Gavilan et al. (2016), were prepared under the following conditions: $\mathrm{C} / \mathrm{O}$ ratio $=1.05$, height above the burner $(\mathrm{HAB})=30 \mathrm{~mm}$. In this paper we present soots prepared under varying flame conditions and $\mathrm{HAB}$ ranging from 18 to $50 \mathrm{~mm}$. We used the following $\mathrm{C} / \mathrm{O}$ ratios and pressures: 0.82 (60 mbar), 1 (28 mbar), 1.05 (33-40 mbar), 1.3 (40 mbar). The deposition time of the films varied from approximately one to four minutes for the closest $\mathrm{HAB}$ of $25 \mathrm{~mm}$ to 1 to $20 \mathrm{~s}$ beyond $30 \mathrm{~mm}$.

\section{UV and IR spectroscopy}

VUV spectra of all samples were recorded in the 120-250 nm range using the APEX branch of the DISCO (dichroism, imaging and spectroscopy for biology) beam line (Giuliani et al. 2009) at the SOLEIL synchrotron. These spectra were completed in the UV-Vis (210-1000 nm) measured with a spectrophotometer (Specord, Analytikjena). The overlapping energy range was used to combine the VUV and UV-Vis datasets. Infrared spectra of the same films were measured using an evacuated fourier transform infrared (FTIR) spectrometer (Bruker Vertex 80V) equipped with a $\mathrm{KBr}$ beam-splitter and a $\mathrm{HgCdTe}$ (mercury cadmium telluride, MCT) detector working in the 4000 to $600 \mathrm{~cm}^{-1}$ ( 2.5 to $15 \mu \mathrm{m}$ ) at $2 \mathrm{~cm}^{-1}$ resolution. The infrared spectra were corrected with a polynomial baseline to subtract the continuum absorption increasing towards higher wavenumbers due to electronic transitions that extend into the infrared. The spectroscopic analysis involved deconvolution of the main electronic bands for the VUV-UV spectra and for the vibrational modes between 3300 and $600 \mathrm{~cm}^{-1}$ for the infrared spectra using the IDL MPFIT routine based on the Levenberg-Marquardt nonlinear least-squares minimization method (Markwardt 2009). The VUV spectra of a sample soot series are shown in Fig. 2. All VUV-MIR spectra and the respective deconvolved features are included in Appendix A.

\subsection{Relationships among the UV fit parameters}

UV-VUV spectra with enough $\mathrm{S} / \mathrm{N}$ were selected and deconvolved using a Lorentzian and three Gaussian functions. We called these the L1, G1, G2, and G3 bands. L1 is the main UV absorption band, falling between 190 to $260 \mathrm{~nm}$, and it is in most cases well-fitted by a single Lorentzian. G1 and G2 are neighboring peaks, appearing around $300 \mathrm{~nm}$ and $190 \mathrm{~nm}$ respectively. G3 is the large UV absorption at around $110 \mathrm{~nm}$. No additional linear background was required for these fits. The resulting fit UV-VUV parameters are summarized in Table A.1 of the electronic version.

\subsubsection{Determination of the optical gap}

We used the visible spectral range (350-1000 nm) to determine the optical band gap of these materials, also known as the Tauc gap. This is often used to characterize the optical properties of amorphous semiconductors (Tauc et al. 1966). The Tauc gap is determined only by the $\pi$-states (mostly or totally delocalized) and is intrinsically related to the energy gap between the valence and conduction bands (Silva et al. 1998). The Tauc gap has also been used to generalize the optical properties of interstellar amorphous carbons (Duley \& Whittet 1992; Jones 2012a). For our samples, the Tauc gap values were obtained by extrapolating the linear region in an $(\alpha \times E)^{1 / 2}$ versus $E$ plot, where $\alpha$ is the absorption coefficient obtained from the relation $\alpha=\tau / h$, where $\tau$ is the optical depth, $h$ the film thickness, and $E$ is in eV. For disordered carbon materials like those presented in this paper, the empirical linear dependance between $\alpha$ and $E$ is expressed by,

$(\alpha \times E)^{1 / 2}=B^{1 / 2}\left(E-E_{\mathrm{g}}\right)$,

where $B$ is a constant attributed to their thermal processing (Jones 2012a). To determine the Tauc gap from the visibleultraviolet spectra, we chose the same region in the visible tail of the Tauc spectra where $2.4<E(\mathrm{eV})<3.2$ to extract the linear fit extrapolated to zero absorption, and from 2.4-2.7 eV and 2.7$3.2 \mathrm{eV}$ to determine the average systematic error bar typically used in soot extinction analysis (Adkins \& Miller 2015). For the soot produced with the $\mathrm{C} / \mathrm{O}=1.05$ flame, $\mathrm{HAB}=34 \mathrm{~mm}$, the fitting linear energy range was shifted to $2.5-3.3 \mathrm{eV}$, in order to avoid a negative gap value. While the thickness of the samples is assumed to be $\sim 30-60 \mathrm{~nm}$ as in Gavilan et al. (2016), this is taken as constant for all samples as it does not significantly affect the gap value determination, whose systematic uncertainty is dominated by the choice of linear energy range. Figure 1 shows the calculated gap values for each film. For the prepared samples, the value of the Tauc optical gap $\left(E_{\mathrm{g}}\right)$ increases from the least hydrogenated soots to the most hydrogenated a-C:H, that is, $0<E_{\mathrm{g}}<2 \mathrm{eV}$. The $\mathrm{H} / \mathrm{C}$ ratio of each sample is obtained from infrared spectra and discussed in Sect. 3.4.

For the a-C:H prepared with a toluene precursor, the optical gap was found to be $1.95 \mathrm{eV}$, lower than the $2.5 \mathrm{eV}$ estimated for the methane-precursor a-C:H of Gavilan et al. (2016). For the soot samples produced with the $\mathrm{C} / \mathrm{O}=0.82$ flame, $E_{\mathrm{g}}$ decreases from 0.78 to $0.62 \mathrm{eV}$ as the $\mathrm{HAB}$ increases. This is the same trend as for the $\mathrm{C} / \mathrm{O}=1$ flame, where $E_{\mathrm{g}}$ decreases from 1.46 to 0.68 , for the $\mathrm{C} / \mathrm{O}=1.05$ flame with a decrease from 1.47 to 0.01 , and for the $\mathrm{C} / \mathrm{O}=1.3$ flame with a decrease from 1.6 to $1 \mathrm{eV}$. Jones (2012a) sequences the family of amorphous carbons based on the optical gap energy, building on previous work by Robertson (1986). Amorphous carbons that are hydrogen rich, called a-C:H, have $E_{\mathrm{g}} \simeq 1.2-2.5 \mathrm{eV}$, while the hydrogen poor carbons, called a-C, have $E_{\mathrm{g}} \simeq 0.4-0.7 \mathrm{eV}$. For our soot samples $E_{\mathrm{g}}<1.6 \mathrm{eV}$, and $E_{\mathrm{g}}=1.95$ for our a-C:H. Thus, Robertson's classification can be further improved by our disordered carbon data.

\subsection{2. $E_{\mathrm{g}}$ versus $\omega_{\mathrm{c}}(\mathrm{L} 1)$}

In Fig. 3 we display the position of the main UV absorption (fitted by a Lorentzian, called L1) against the optical gap, yielding the relation,

$E_{\mathrm{g}}[\mathrm{eV}]=0.76 \pm 0.3 \times \omega_{\mathrm{c}}(\mathrm{L} 1)\left[\mu \mathrm{m}^{-1}\right]-3.1 \pm 0.5$.

These two parameters have a linear Pearson correlation coefficient $r=0.91$. The wide variation in the position of the L1 peak from 3.8 to $5.2 \mu \mathrm{m}^{-1}$ (192 to $262 \mathrm{~nm}$ ) is consistent with previous experimental works where the UV peak is centered between 180 and $280 \mathrm{~nm}$ (Llamas Jansa et al. 2003). Russo et al. (2014) found that the spectral features in the UV-visible range are mainly affected by the higher molecular weight species of combustion flame products. Because L1 is strongly correlated to the optical gap $E_{\mathrm{g}}$, variations in the position of $\mathrm{L} 1$ can be attributed to changes in the nanostructuration due to varying $\mathrm{H} / \mathrm{C}$, $\mathrm{sp}^{3} / \mathrm{sp}^{2}$, and the size of the polyaromatic units, which will be discussed in the following sections. The Tauc optical gap model, 


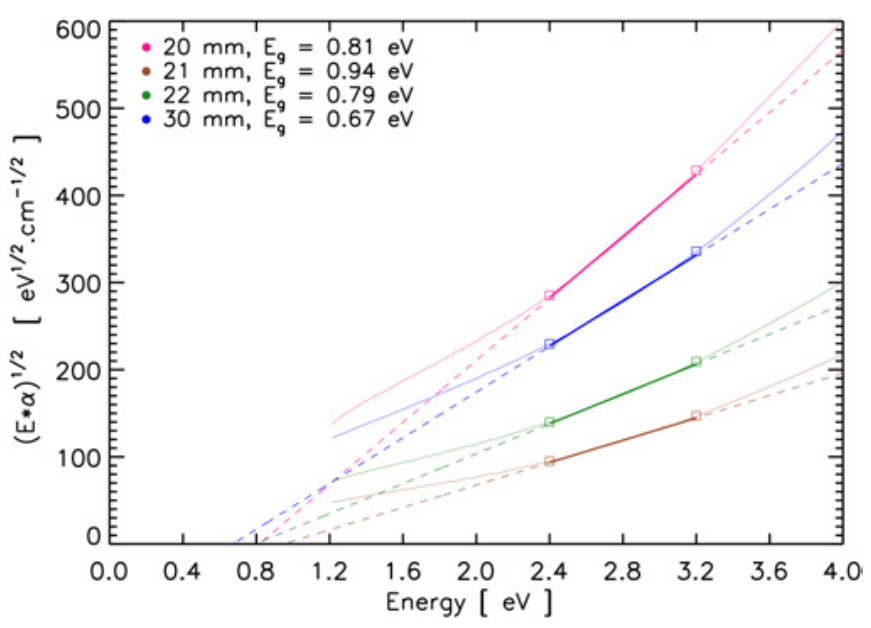

(a) Combustion flame with $\mathrm{C} / \mathrm{O}=0.82$

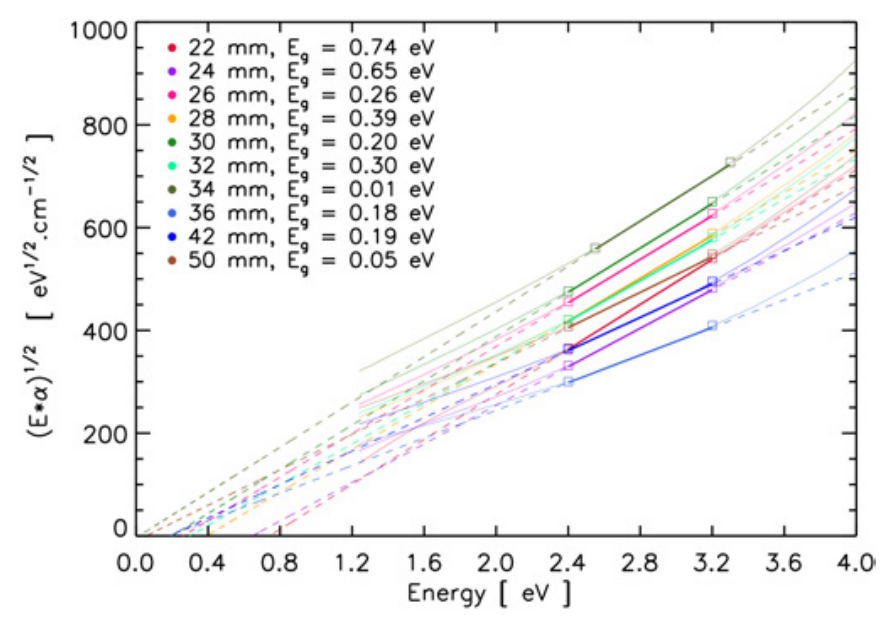

(c) Combustion flame with $\mathrm{C} / \mathrm{O}=1.05$

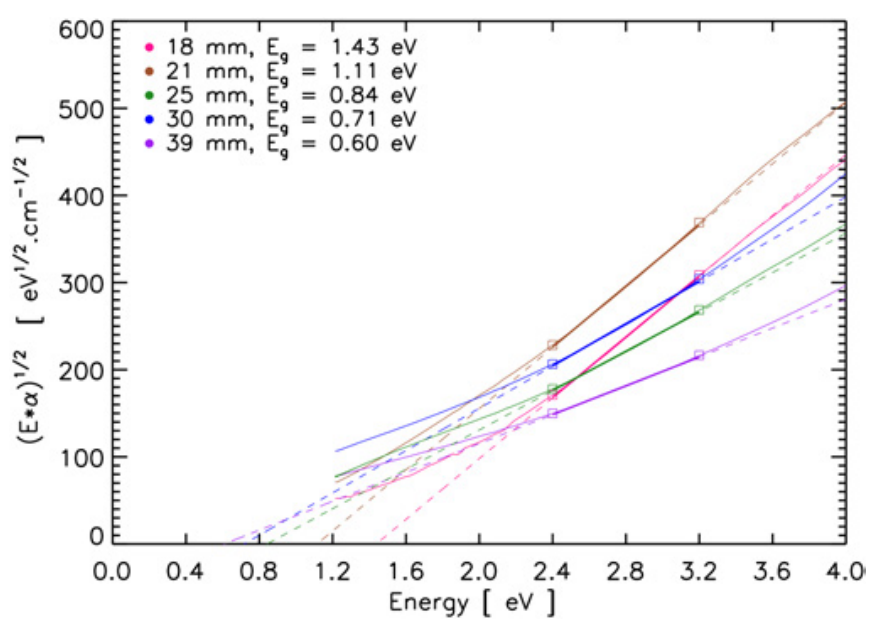

(b) Combustion flame with $\mathrm{C} / \mathrm{O}=1$

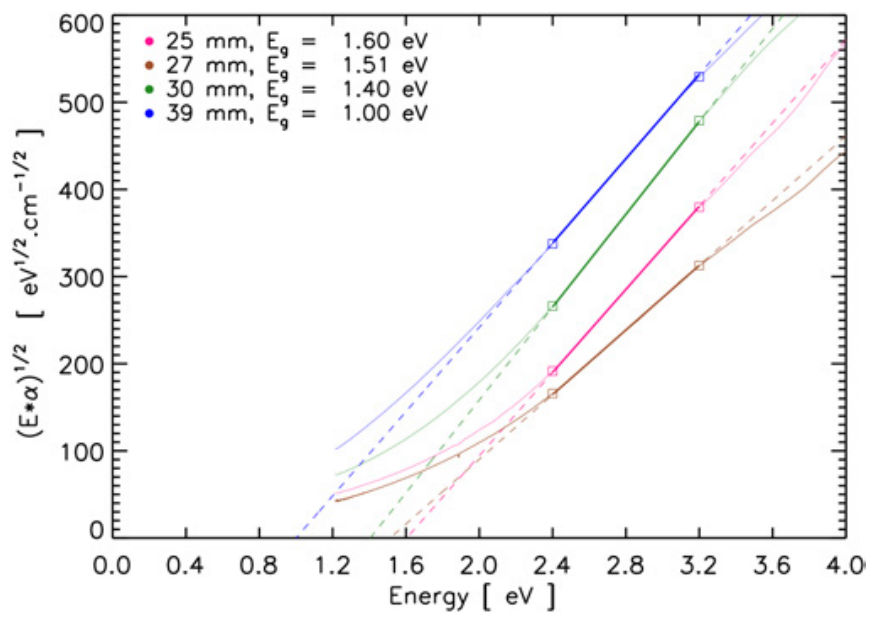

(d) Combustion flame with $\mathrm{C} / \mathrm{O}=1.3$

Fig. 1. Tauc optical gap extrapolation using the visible spectra for soot samples prepared with different C/O flame ratios and collected at varying heights above the burner (HAB in $\mathrm{mm}$ ).

which has been used to give a complete description of the optical properties of carbonaceous materials (Robertson \& O'Reilly 1987; Robertson 1991; Jones 2012a), appears to be well-suited for our soot samples.

From now on, our fitting parameters will be compared to the parameters of the interstellar $217.5 \mathrm{~nm}$ UV bump (Fitzpatrick \& Massa 2005, 2007), that is, $\omega_{\mathrm{c}}=4.593 \mu \mathrm{m}^{-1}$ with $\sigma=0.0191 \mu \mathrm{m}^{-1}$ and $F W H M=0.77-1.29 \mu \mathrm{m}^{-1}$ with $\sigma=$ $0.050 \mu \mathrm{m}^{-1}$. We also compare our parameters to the average position of the circumstellar $\sim 240 \mathrm{~nm}$ UV bump, as determined by observations of the circumstellar envelopes of C-rich stars like V348 Sagittarii (Drilling et al. 1997). For the average circumstellar UV bump, $\omega_{\mathrm{c}}=4.12 \mu \mathrm{m}^{-1}$, limited from $4 \mu \mathrm{m}^{-1}$ (Blanco et al. 1995) up to $4.4 \mu \mathrm{m}^{-1}$ (Waelkens et al. 1995), and a $F W H M=1.34 \mu \mathrm{m}^{-1}$ with $\sigma=0.06 \mu \mathrm{m}^{-1}$ (Drilling et al. 1997). The spectral parameters of our samples will be preferably plotted against the position of L1, $\omega_{\mathrm{c}}(\mathrm{L} 1)$, strongly correlated to $E_{\mathrm{g}}$, as L1 (rather than $E_{\mathrm{g}}$ ) is the direct spectroscopic parameter.

\subsection{3. $\gamma(\mathrm{L} 1)$ versus $\omega_{\mathrm{c}}(\mathrm{L} 1)$}

As seen in Fig. 4, an anti-correlation is found between the FWHM $\gamma(\mathrm{L} 1)$ and $\omega_{\mathrm{c}}(\mathrm{L} 1)(r=-0.79)$, while $\gamma(\mathrm{L} 1)$ versus $E_{\mathrm{g}}$ is also anti-correlated $(r=-0.72)$. This result contrasts

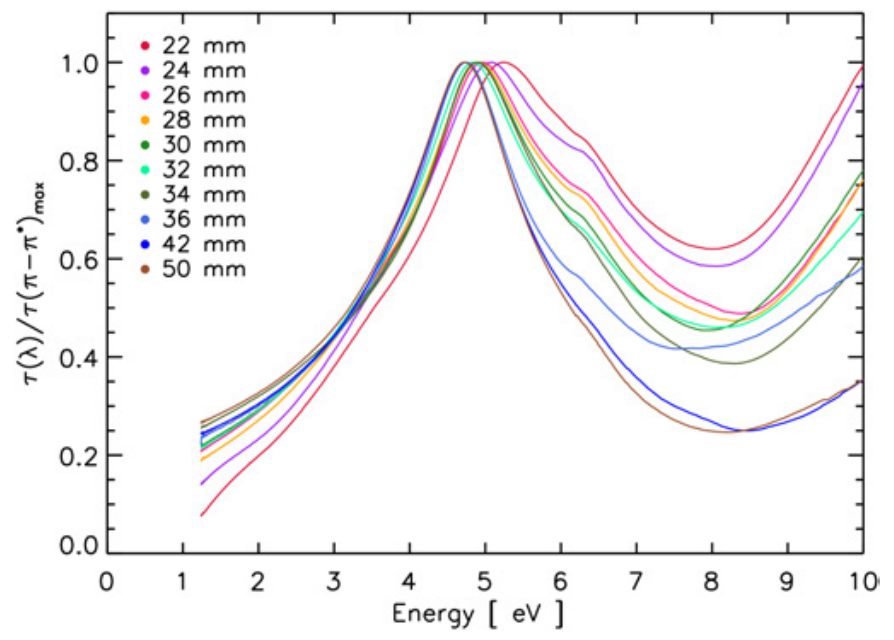

Fig. 2. VUV-Visible spectra of a series of soot nanoparticle films $(\mathrm{C} / \mathrm{O}=$ $1.05, \mathrm{HAB}=22-50 \mathrm{~mm}$ ). These have been normalized by the maximum optical depth of their respective $\pi-\pi^{*}$ electronic band.

with the non-correlation between both parameters in extinction curves found by Fitzpatrick \& Massa (2005). The large scatter in FWHM has been suggested to be due to grain clustering 


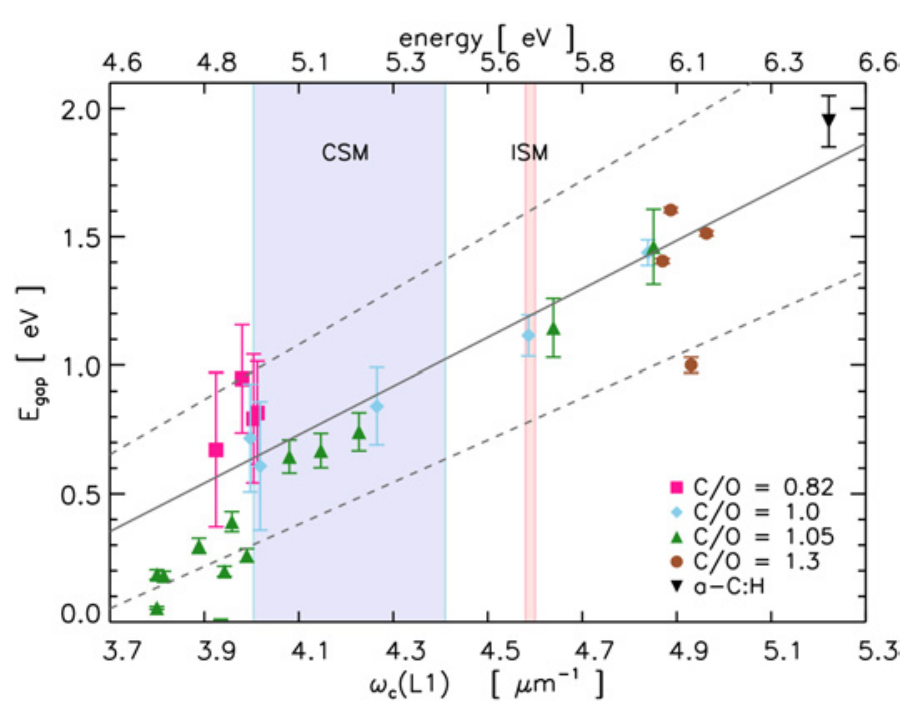

Fig. 3. Tauc optical gap, $E_{\mathrm{g}}$, for our laboratory samples versus the center of the $\pi-\pi^{*}$ electronic transition, $\omega_{\mathrm{c}}(\mathrm{L} 1)$. The latter is used as our main spectroscopic parameter in the UV.

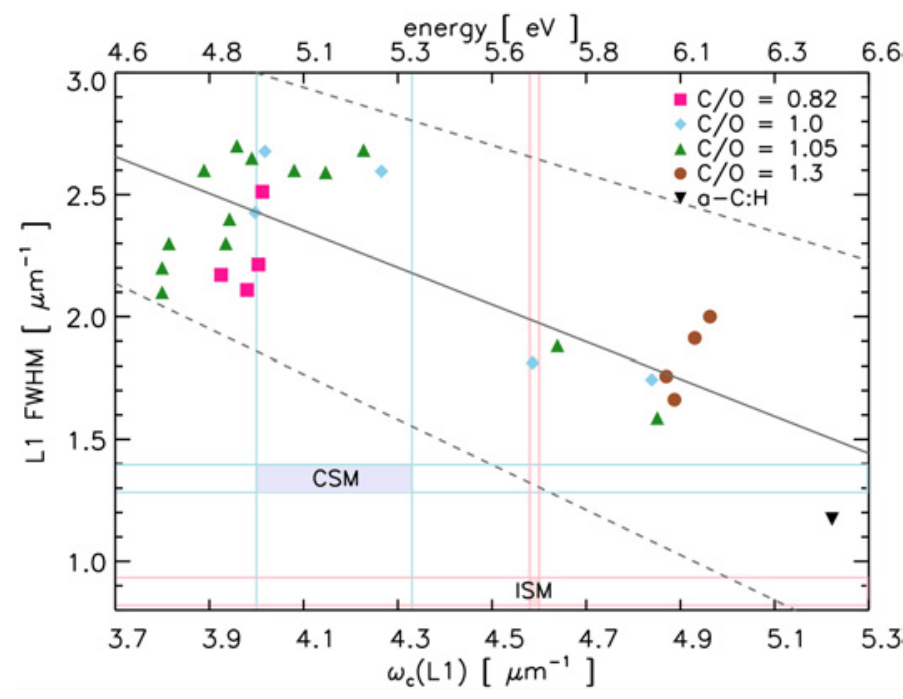

Fig. 4. FWHM of the $\pi$ - $\pi^{*}$ electronic transition, $\gamma(\mathrm{L} 1)$, versus its center position, $\omega_{\mathrm{c}}(\mathrm{L} 1)$, showing a clear correlation, absent in interstellar extinction curves (Fitzpatrick \& Massa 2005).

broadening (Schnaiter et al. 1998). From all our samples, only one has an L1 peak within the observed ISM FWHM parameter range, the a-C:H prepared with toluene, with $\gamma(\mathrm{L} 1)=1.2 \mu \mathrm{m}^{-1}$, but it is centered at $5.2 \mu \mathrm{m}^{-1}$ and not at the expected $4.6 \mu \mathrm{m}^{-1}$. However, if we consider a different parametrization of the interstellar UV bump (Sect. 4), two soot samples are more representative, $\mathrm{C} / \mathrm{O}=1(\mathrm{HAB}=21 \mathrm{~mm})$ and $\mathrm{C} / \mathrm{O}=1.05(\mathrm{HAB}=$ $18 \mathrm{~mm})$.

\subsection{4. $\omega_{\mathrm{c}}(\mathrm{G} 1, \mathrm{G} 2, \mathrm{G} 3)$ versus $\omega_{\mathrm{c}}(\mathrm{L} 1)$}

In Fig. 5 we plot the positions of the main electronic transitions measured in the UV and VUV. G1 and G2 are absorption peaks in the neighborhood of L1. We can see that each electronic transition falls within a particular energy range for all samples: G1 peaks are constrained between 4.8 and $5.7 \mu \mathrm{m}^{-1}$ while G2 peaks fall between 3 and $4 \mu \mathrm{m}^{-1}$. The G1 and G2 transitions rarely appear simultaneously. The position of the G3 peak falls

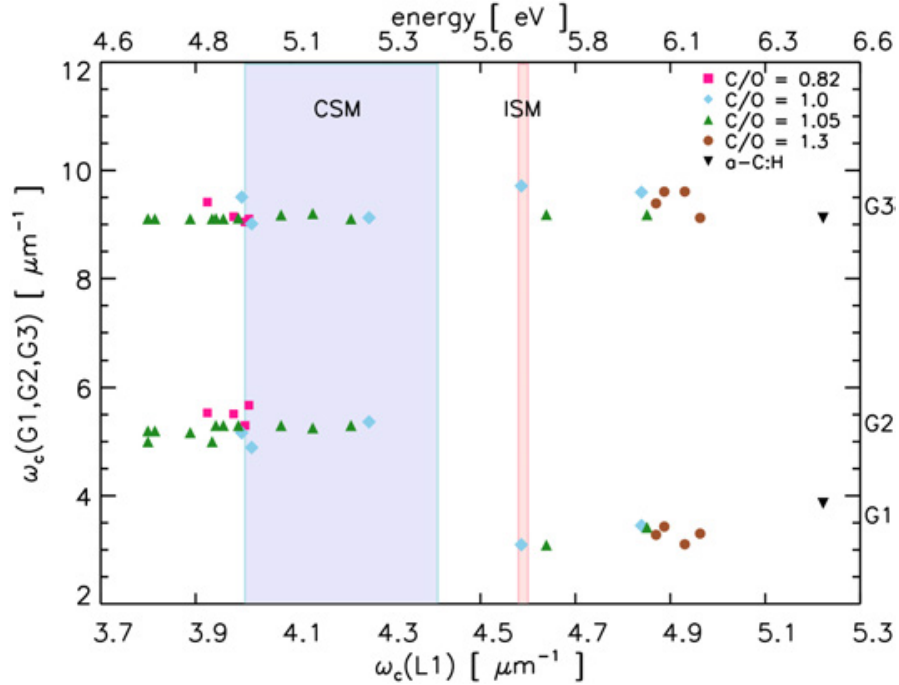

Fig. 5. Positions of the UV and VUV major electronic transitions, $\omega_{\mathrm{c}}(\mathrm{G} 1), \omega_{\mathrm{c}}(\mathrm{G} 2), \omega_{\mathrm{c}}(\mathrm{G} 3)$, versus the center of the $\pi-\pi^{*}$ electronic transition $\omega_{\mathrm{c}}(\mathrm{L} 1)$. For all samples presented here the positions of these peaks fall at precise energies, with little dispersion, but their relative intensities tend to vary strongly.

consistently at an average of $9 \mu \mathrm{m}^{-1}$. The ratio of the integrated $\mathrm{G} 3$ band to the $\mathrm{L} 1$ feature averages $2.0 \pm 0.8$.

\subsection{Relationships among the UV and mid-IR fit parameters}

To complement the UV and VUV fit parameters, a detailed band analysis of the C-H stretching mode region $\left(3100-2700 \mathrm{~cm}^{-1}\right)$ and bending mode region $\left(1800-500 \mathrm{~cm}^{-1}\right)$ was performed. The out of plane (OOP) bending modes in the 900 to $700 \mathrm{~cm}^{-1}(11$ to $15 \mu \mathrm{m})$ are generally used for the classification of the aromatic ring edge structures (Russo et al. 2014), but these are only present in the soots prepared in flames with $\mathrm{C} / \mathrm{O}=0.82$ and 1.05. The mid-infrared attributions are found in previous soot studies (Carpentier et al. 2012; Dartois et al. 2007). Generally, the bending mode region is $\sim 1.5-4$ times more absorbing than the stretching mode region for the soot samples. In a few cases, the integrated intensities of these modes were normalized to the most intense mode of the respective region for intercomparison between samples, to account for thickness variations between samples. The resulting fitted mid-infrared parameters are summarized in Table A. 2 of the electronic version.

\subsection{1. $\omega_{\mathrm{c}}\left(\mathrm{sp}^{3}\right.$ defect) versus $\omega_{\mathrm{c}}($ arom. $\mathrm{C}=\mathrm{C}$ stretch. $)$}

In Fig. 6, we show the strong correlation $\left(r^{2}=0.89\right)$ between the $\omega_{\mathrm{c}}($ aromatic $\mathrm{C}=\mathrm{C}$ stretch $)$ and $\omega_{\mathrm{c}}\left(\mathrm{sp}^{3}\right.$ defect $)$ band positions, confirming previous findings (Carpentier et al. 2012). This relation traces differences in shapes and structures of the polyaromatic units in the soot. For polyaromatic carbons, three astrophysical AIB classes are proposed based on their spectra in the 6 to $9 \mu \mathrm{m}^{-1}$ region (Peeters et al. 2002). According to this classification, our laboratory soots correspond to classes B and C of the AIBs.

\subsection{2. $\omega_{\mathrm{c}}\left(\mathrm{sp}^{3}\right.$ defect) $\& \omega_{\mathrm{c}}\left(\right.$ arom. $\mathrm{C}=\mathrm{C}$ stretch.) versus $\omega_{\mathrm{c}}(\mathrm{L} 1)$}

The $\mathrm{sp}^{3}$ defect band is assigned to edge defects that can occur due to aliphatic cross-linking and as non-hexagonal rings 


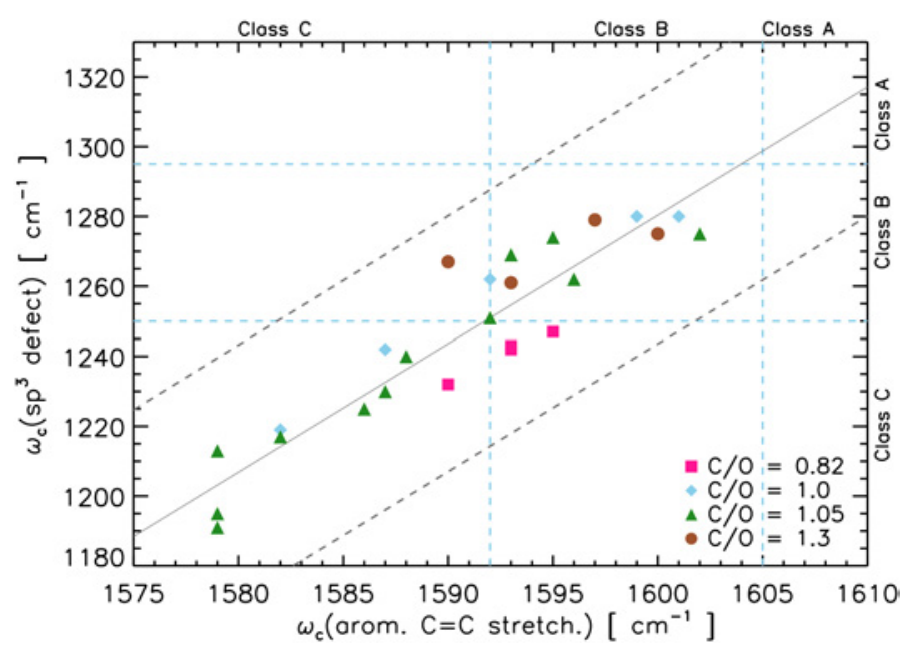

Fig. 6. Correlation between the carbon defect band, $\omega_{c}\left(\mathrm{sp}^{3}\right.$ defect), versus the aromatic $\mathrm{C}=\mathrm{C}$ stretching band, $\omega_{\mathrm{c}}(\mathrm{C}=\mathrm{C})$, verifying previous findings in other soot samples (Carpentier et al. 2012).

carbon defects (Carpentier et al. 2012) and contribute to electronic intra-band states of the material. For our samples, this band appears between $1190-1280 \mathrm{~cm}^{-1}$.

In Fig. $7 \mathrm{a}$ we plot the position of the $\mathrm{sp}^{3}$ defect band versus the center of the L1 peak, which correlates well for all of our samples. From this relation, the L1 position of the CSM bump would correspond to an $\mathrm{sp}^{3}$ defect located $\sim 1260 \mathrm{~cm}^{-1}$ (i.e., class $\mathrm{B} / \mathrm{C}$ carrier), while for the ISM bump we expect it to be found $\sim 1280 \mathrm{~cm}^{-1}$ (i.e., class B carrier).

In Fig. $7 \mathrm{~b}$ we plot the position of the aromatic $\mathrm{C}=\mathrm{C}$ band versus the center of the L1 peak, also well correlated, as expected from the relation found in Fig. 6. For the a-C:H, the $\mathrm{C}=\mathrm{C}$ band is found at $1625 \mathrm{~cm}^{-1}$ and for the soot with the highest $E_{\mathrm{g}}$ it is found at $1590 \mathrm{~cm}^{-1}$. As the value of $E_{\mathrm{g}}$ decreases (and the $\mathrm{H} / \mathrm{C}$ ratio of the sample decreases), the position shifts down to $1575 \mathrm{~cm}^{-1}$. The correlation is linear up to L1 positions $\sim 4.7 \mu \mathrm{m}^{-1}$. At higher energies this correlation shows a larger scatter. For the L1 position of the CSM bump, we would expect the $\mathrm{C}=\mathrm{C}$ vibrational mode to be located at $\sim 1592 \mathrm{~cm}^{-1}$ while for the ISM bump, we expect the defect to be found near $1600 \mathrm{~cm}^{-1}$. It is then not surprising that the $\mathrm{sp}^{3}$ defect and $\mathrm{C}=\mathrm{C}$ band positions correlate with the position of $\mathrm{L} 1$ as they are all sensitive to the electrons' delocalizations in $\mathrm{sp}^{2}$ conjugated systems.

\subsection{Origin of $U V$ features $G 1$ and $G 2$}

\subsection{1. $A(\mathrm{G} 1) / A(\mathrm{C}=\mathrm{O})$ versus $\omega_{\mathrm{c}}(\mathrm{L} 1)$}

$\mathrm{G} 1$ is a minor peak appearing for some soots $(\mathrm{C} / \mathrm{O}=1.3$, for all distances from the burner, $\mathrm{C} / \mathrm{O}=1.05$ for 14 and $18 \mathrm{~mm}$ ) and for the a-C:H. To identify the origin of the $\mathrm{G} 1$ peak present in some UV spectra (for flames with $\mathrm{C} / \mathrm{O}$ ratios $=1,1.05$ and 1.3), we plotted the Lorentzian position versus the ratio of the areas of $A(\mathrm{G} 1)$ to $A(\mathrm{C}=\mathrm{O})$, showing that this feature appears for a certain type of carbon, whose main $\pi-\pi^{*}$ band appears at $\omega_{\mathrm{c}}$ (L1) $>4.6 \mu \mathrm{m}^{-1}$.

We choose the thickest films, where the carbonyl mode is clearly observed, to identify the origin of G1. These samples correspond to flames with $\mathrm{C} / \mathrm{O}=1,1.05$. The flame with $\mathrm{C} / \mathrm{O}$ $=1.3$ produced very thin films where oxidation is surface dominated. By plotting the ratio of the $\mathrm{G} 1$ feature to the $\mathrm{L} 1$ feature in the UV to the ratio of the integrated $\mathrm{C}=\mathrm{O}$ to the $\mathrm{C}=\mathrm{C}$ mode, a weak correlation arises. By following the evolution of

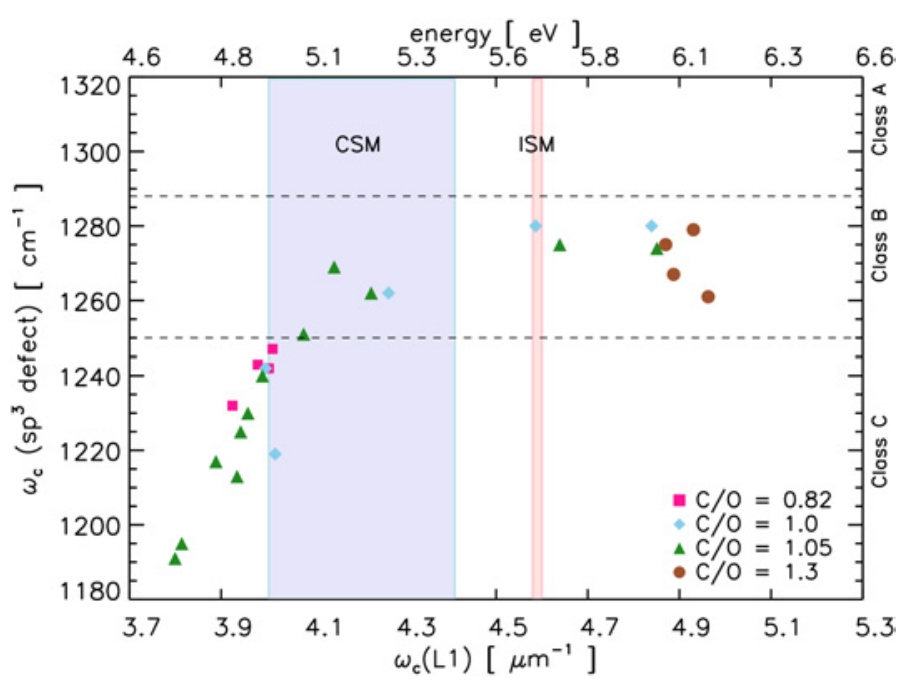

(a)

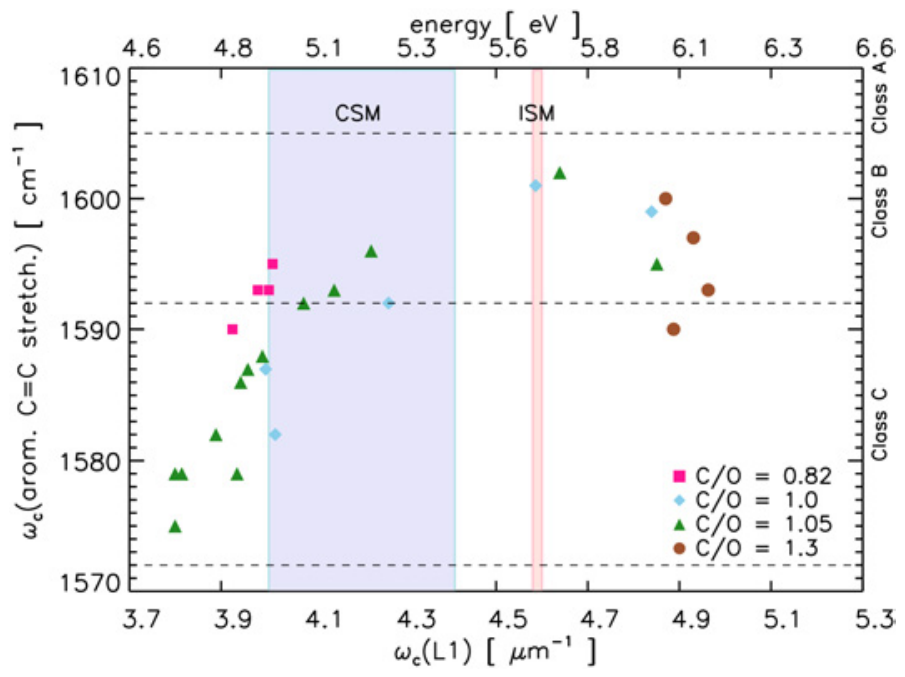

(b)

Fig. 7. Aromatic infrared bands (AIBs) in our laboratory soot samples. $a) \omega_{\mathrm{c}}\left(\mathrm{sp}^{3}\right.$ defect) versus $\left.\omega_{\mathrm{c}}(\mathrm{L} 1) . b\right) \omega_{\mathrm{c}}(\operatorname{arom} . \mathrm{C}=\mathrm{C}$ stretch.) versus $\omega_{\mathrm{c}}(\mathrm{L} 1)$. The laboratory found band positions for the $\mathrm{sp}^{3}$ defect and aromatic $\mathrm{C}=\mathrm{C}$ band are compared to the classification of AIBs by (Peeters et al. 2002). Our laboratory samples are classified as Class B and Class C AIBs. The inferred CSM UV bump carriers fall within Class $\mathrm{B} / \mathrm{C}$, and the ISM UV bump carriers approaches the A/B class.

the mid-infrared and UV spectra for the flame with $\mathrm{C} / \mathrm{O}=1$ in the series of Figs. A.1-A.7, as soon as the intensity of $\mathrm{C}=\mathrm{O} \ll$ $\mathrm{C}=\mathrm{C}$, the UV G1 peak disappears. The G1 peak can be assigned to the oxidation of the younger soots produced near the burner, as traced by the $\mathrm{C}=\mathrm{O}$ infrared intensities.

\subsection{2. $A(\mathrm{G} 2) / A\left(\mathrm{CH}_{\text {arom. }}\right)$ versus $\omega_{\mathrm{c}}(\mathrm{L} 1)$}

G2 is a minor peak appearing for some soots $(\mathrm{C} / \mathrm{O}=1$, beyond 25-39 mm, $\mathrm{C} / \mathrm{O}=1.05$, beyond $22 \mathrm{~mm})$ at $\sim 5.3 \mu \mathrm{m}^{-1}(180 \mathrm{~nm})$. This peak appears as the soots are collected farther from the burner, that is, when they are more mature soots with polyaromatic structures or fullerene-like soots (Carpentier et al. 2012). Gadallah et al. (2011) and Llamas Jansa et al. (2003) attributed this peak to carbonyl vibrations. We propose a different attribution. We divided the integrated area of G2 by the integrated area of the aromatic $=\mathrm{CH}$ stretching mode, and confirm that $\mathrm{G} 2$ appears only when the intensity of the $\mathrm{sp}^{3}$ defect $\gg \mathrm{C}=\mathrm{C}$ band 


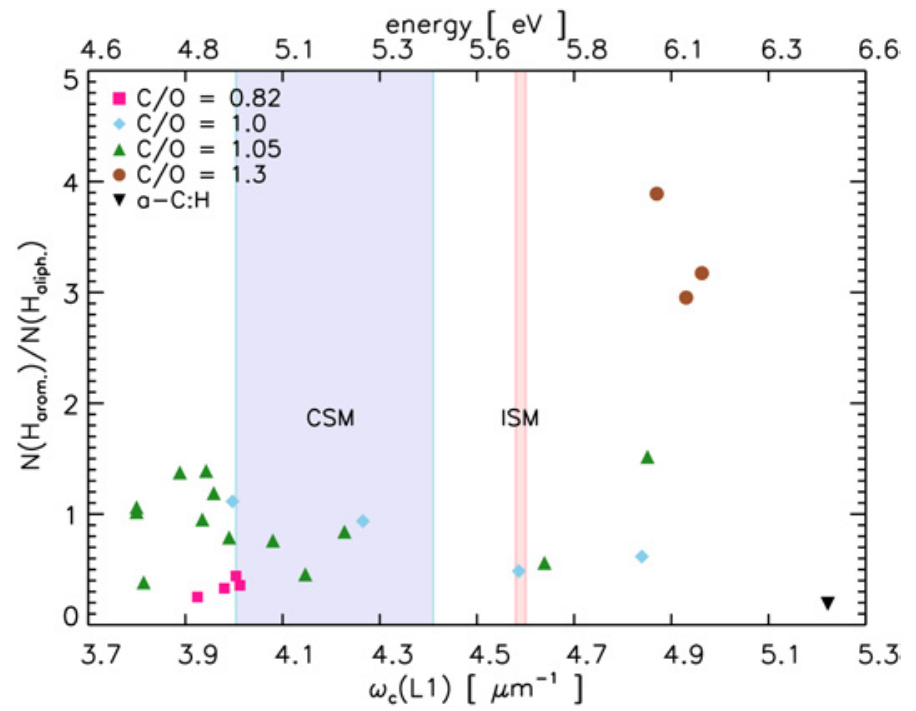

Fig. 8. Aromatic to aliphatic hydrogen ratio versus $\omega_{\mathrm{c}}(\mathrm{L} 1)$, determined from the integrated infrared $=\mathrm{CH}$ and $-\mathrm{CH}_{2,3}$ stretching modes, corrected by the ratio of the corresponding oscillator strengths.

and for $\omega_{\mathrm{c}}(\mathrm{L} 1)<4.3 \mu \mathrm{m}^{-1}$, corresponding to the lower Tauc gap materials, that is, low $\mathrm{H} / \mathrm{C}$ soots where defects abound.

\section{4. $\mathrm{H} / \mathrm{C}$ ratios}

The mid-infrared spectra of different carbonaceous samples reveal the carbon hybridization states and allow us to discriminate between aliphatic and aromatic hydrogen. The $\mathrm{C}-\mathrm{H}$ stretching peaks in the $3100-2900 \mathrm{~cm}^{-1}$ allow us to determine the aromatic to aliphatic hydrogen ratio. We take the ratio of the integrated $\mathrm{CH}_{\text {aromatic }}\left(\sim 3040 \mathrm{~cm}^{-1}\right)$ to the $\mathrm{CH}_{\text {aliphatic }}$ modes $\left(\mathrm{CH}_{2}\right.$ asymmetric stretching mode, $\sim 2920 \mathrm{~cm}^{-1}$ including the Fermi resonance and the $\mathrm{CH}_{3}$ asymmetric mode at $\sim 2960 \mathrm{~cm}^{-1}$ ) normalized by their oscillator strengths, $A\left(\mathrm{CH}_{\text {arom }}\right)=1.9 \times 10^{-18} \mathrm{~cm} /$ group, $A\left(\mathrm{CH}_{2, \text { as. }}\right)=8.4 \times 10^{-18} \mathrm{~cm} /$ group, and $A\left(\mathrm{CH}_{3, \text { as }}\right)=1.25 \times$ $10^{-17} \mathrm{~cm} /$ group (Dartois et al. 2007). With the exception of a single sample $(\mathrm{C} / \mathrm{O}=1, d=18 \mathrm{~mm})$, most spectra show a dominance of methylene $\left(=\mathrm{CH}_{2}\right)$ over methyl $\left(-\mathrm{CH}_{3}\right)$ groups. The resulting ratio is shown in Fig. 8 plotted against the central position of L1, resulting in a large scatter. This is also the case for the ratio of the areas of $\mathrm{CH}_{\text {arom. }}$ to the sum of the areas of $\left(\mathrm{CH}_{\text {aliph. }}+\right.$ $\mathrm{CH}_{\text {arom. }}$ ). We note in particular the case for soots produced in the $\mathrm{C} / \mathrm{O}=1.3$ flame, where the aromatic to aliphatic hydrogen ratio is an order of magnitude greater than in most other materials.

Carbonaceous materials containing hydrogen can be classified in terms of the hydrogen to carbon ratio (Robertson \& O'Reilly 1987). To find a representative experimental H/C ratio for our samples, we have considered different combinations of vibrational modes in the infrared spectra. An empirical parameter of the $\mathrm{H} / \mathrm{C}$ content in our samples is found by taking the ratios of the integrated intensities of the $\mathrm{CH}_{\text {arom }}$ mode to that of the aromatic $\mathrm{C}=\mathrm{C}$ stretching mode $\left(\sim 1600 \mathrm{~cm}^{-1}\right)$, (taking $A(\mathrm{C}=\mathrm{C}) \sim 0.175 \times 10^{-18} \mathrm{~cm} /$ group, Joblin et al. 1994). We call this the aromatic $\mathrm{H} / \mathrm{C}$ ratio. Using the empirically found aromatic $\mathrm{H} / \mathrm{C}$ ratios and the aromatic+aliphatic $\mathrm{H} / \mathrm{C}$ ratio, that is, $N\left(\mathrm{CH}_{\text {arom. }}+\mathrm{CH}_{2,3, \text { as }}\right) / N(\mathrm{C}=\mathrm{C})$, we calculate $\mathrm{X}_{\mathrm{H}}$, defined as,

$X_{\mathrm{H}}=\frac{\mathrm{H} / \mathrm{C}}{1+\mathrm{H} / \mathrm{C}}$

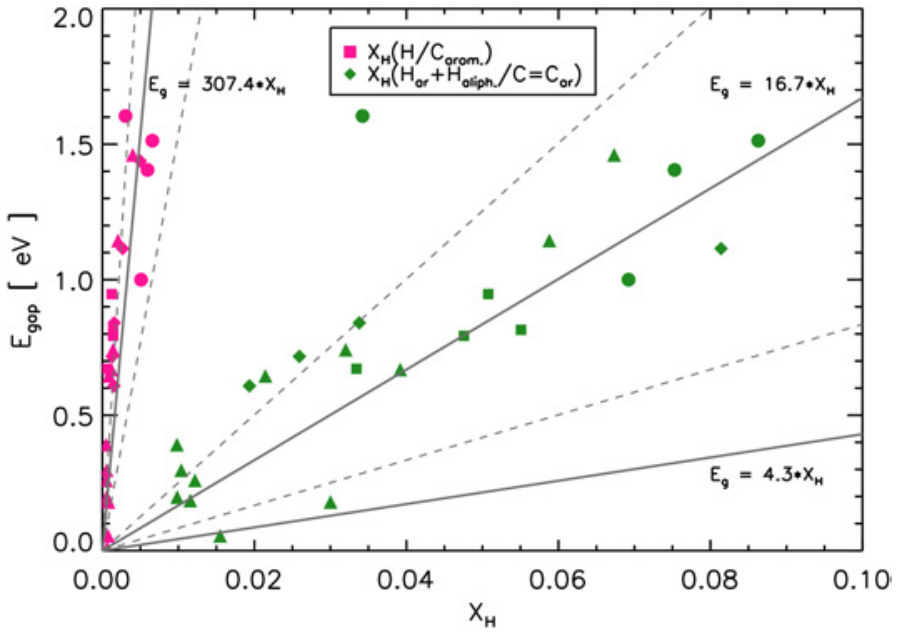

Fig. 9. Empirically found $E_{\mathrm{g}}$ versus $\mathrm{X}_{\mathrm{H}}$. We used the aromatic $\mathrm{H} / \mathrm{C}$ ratio and aromatic+aliphatic $\mathrm{H} / \mathrm{C}$ ratio, presented as two linear fits for the hydrogen poor (low $E_{\mathrm{g}}$ ) regime (only soots). When both aromatic and aliphatic $\mathrm{CH}$ modes are included, our linear fit approaches the coefficient found for amorphous carbon in Tamor \& Wu (1990). The shape of the symbols corresponds to those used in Fig. 8.

The result is shown in Fig. 9. Two linear trends are found for the hydrogen poor $(\mathrm{H} / \mathrm{C} \ll 1)$ carbonaceous samples (soots).

Tamor \& $\mathrm{Wu}$ (1990) provided an empirical linear relationship between the band gap and the $\mathrm{H} / \mathrm{C}$ ratios of a-C:H materials with $E_{\mathrm{g}}=1.2-2 \mathrm{eV}$, where,

$E_{\mathrm{g}}(\mathrm{eV}) \simeq 4.3 X_{\mathrm{H}}$.

If we only consider the aromatic $\mathrm{H} / \mathrm{C}$ ratio, the coefficient is about 100 times larger than the one found by Tamor \& Wu (1990). If we include the aliphatic contribution, the fitted slope is still approximately four times larger. Although Eq. (5) is applicable to a-C:H materials with $E_{\mathrm{g}}=1.2-2 \mathrm{eV}$ and our soots have gaps between 0.01 to $1.60 \mathrm{eV}$, our materials show a linear relationship between the $\mathrm{H} / \mathrm{C}$ ratio and the gap. This demonstrates that not only knowledge of hydrogen bonding but also knowledge of the carbon coordination is essential to understand the physical and chemical structure of carbonaceous materials. For low gap materials, Tamor \& Wu's relationship no longer holds. The evolution of the properties between low gap and high gap materials should be taken into account in optical models of astrophysical carbon.

\subsection{Carbon structure}

\subsection{1. $L_{\mathrm{a}}$ and $N_{\text {rings }}$ versus $\omega_{\mathrm{c}}(\mathrm{L} 1)$}

The $E_{\mathrm{g}}$ parameter can be used to unveil the structural properties of aromatic absorbers in amorphous carbons (Robertson \& O'Reilly 1987; Robertson 1991), including the average coherence length, $L_{\mathrm{a}}$ (size of the polyaromatic units), and the number of aromatic rings, $N_{\mathrm{R}}$, for the largest clusters contributing to the electronic density of states, although not necessarily the most abundant ones (Gadallah et al. 2011). An empirical relation between $L_{\mathrm{a}}$ and $E_{\mathrm{g}}$ was proposed by Robertson (1991),

$L_{a}(\mathrm{~nm})=\left[\frac{0.77}{E_{\mathrm{g}}(\mathrm{eV})}\right]$.

A similar empirical relation was proposed for a single graphene sheet where the number of six-fold aromatic rings, 


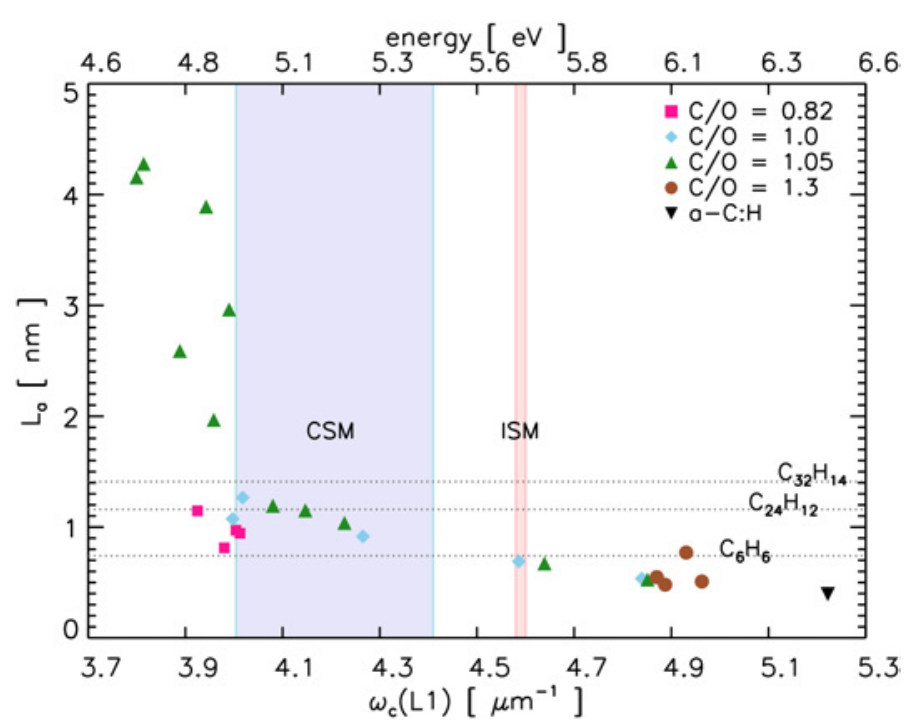

Fig. 10. Average coherence length, $L_{\mathrm{a}}$, of polyaromatic units of selected laboratory carbons $\left(L_{\mathrm{a}}<5 \mathrm{~nm}\right)$ versus $\omega_{\mathrm{c}}(\mathrm{L} 1)$. For comparison, we included the coherence length of Benzene $\left(\mathrm{C}_{6} \mathrm{H}_{6}\right)$, Coronene $\left(\mathrm{C}_{24} \mathrm{H}_{12}\right)$, and Ovalene $\left(\mathrm{C}_{32} \mathrm{H}_{14}\right)$ found at http: //pah.nist. gov.

$N_{\mathrm{R}}$, can be derived from $E_{\mathrm{g}}$ according to the model by Robertson \& O'Reilly (1987), in which the gap energy decreases as a function of the size of the graphene layers via the following relation,

$N_{\mathrm{R}}=\left[\frac{5.8}{E_{\mathrm{g}}(\mathrm{eV})}\right]^{2}$.

We have plotted the $E_{\mathrm{g}}$ derived $N_{\mathrm{R}}$ and $L_{\mathrm{a}}$ values against the position of the main UV bump (also strongly correlated to $E_{\mathrm{g}}$ ) as shown in Figs. 10 and 11. When the position of the L1 peak shifts towards the UV, towards a larger band gap, $L_{\mathrm{a}}$ and $N_{\mathrm{R}}$ decrease. For the interstellar UV bump this would correspond to about 25 rings in a polyaromatic unit, and to 65 rings for the circumstellar bump. For the aromatic coherence length, we infer $\sim 0.7 \mathrm{~nm}$ for the interstellar bump carrier and $\sim 1 \mathrm{~nm}$ for the circumstellar bump carrier. Our soots consist of $L_{a}=0.5$ to $3.3 \mathrm{~nm}$ nanoparticles with corresponding band gaps of $E_{\mathrm{g}}=0.1-1.6 \mathrm{eV}$. The smallest aromatic length $L_{a}=0.4 \mathrm{~nm}$ was found for the a-C:H with $E_{\mathrm{g}}=2 \mathrm{eV}$.

\subsection{2. $\mathrm{H} / \mathrm{C}$ versus $L_{\mathrm{a}}$ and $N_{\text {rings }}$}

We use empirical relationships between the number of rings and the $\mathrm{H} / \mathrm{C}$ ratio of our materials and compare them to purely aromatic carbons, that is, PAHs. In circum-PAHs, PAH with condensed six-membered rings (Violi et al. 2002), the number of rings grows in a sequence as follows: $N_{\text {rings }}=1,7,19,37,61$, 91 , with corresponding $\mathrm{H} / \mathrm{C}$ ratios $=1,0.5,0.33,0.25,0.2,0.17$. To compare the structure of our soots to these PAHs, we will use the relation found in Jones (2012b) to evaluate the radius of the most compact aromatic domains, equivalent to $L_{\mathrm{a}}$ for the circum-PAHs,

$\left.a_{\mathrm{R}}(\mathrm{nm})=0.09 \times\left(2 \times N_{\mathrm{R}}+\sqrt{(} N_{\mathrm{R}}\right)+0.5\right)^{0.5}$.

As show in Fig. 12 our samples are, as expected, much less hydrogenated than circum-PAHs. For these soots, $L_{\mathrm{a}}$ ranges from 0.3 to $10 \mathrm{~nm}$, while the number of rings in a polyaromatic unit spans from approximately one for the most hydrogenated soot

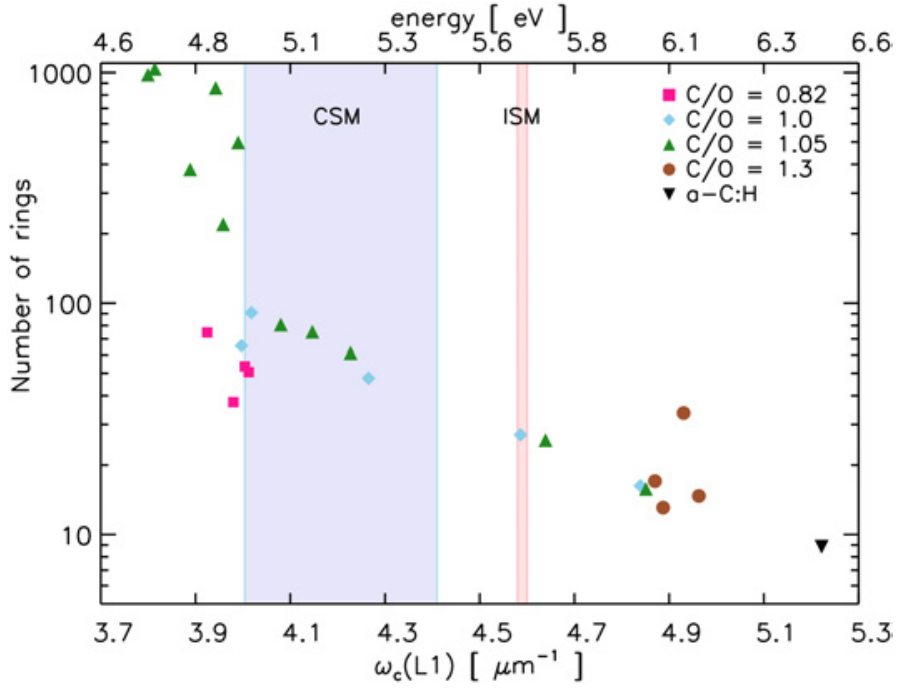

Fig. 11. Number of rings, $N_{\mathrm{R}}$, in the polyaromatic units of our laboratory carbons versus $\omega_{\mathrm{c}}(\mathrm{L} 1)$ suggesting $N_{\mathrm{R}} \sim 60$ for the CSM bump and $N_{\mathrm{R}} \sim 25$ for the ISM bump.

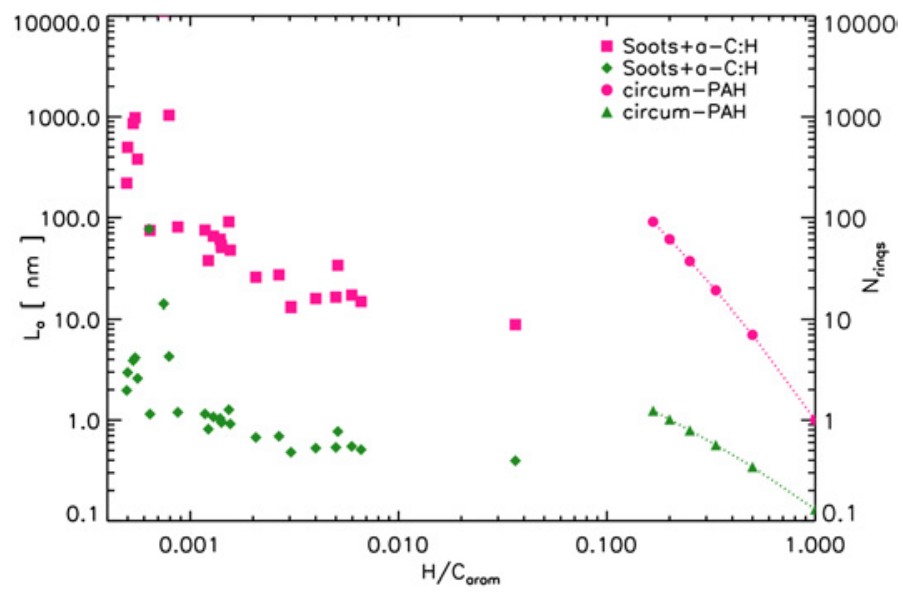

Fig. 12. Average coherence length, $L_{\mathrm{a}}$, and number of rings, $N_{\mathrm{R}}$, in the polyaromatic units of our laboratory carbons and circum-PAHs versus the corresponding aromatic $\mathrm{H} / \mathrm{C}$ ratio.

sample to 1000 for the least hydrogenated. Both $L_{\mathrm{a}}$ and $N_{\mathrm{R}}$ decay exponentially as a function of the aromatic $\mathrm{H} / \mathrm{C}$ ratio following the same trend as PAHs. Similarly, to find the number of carbon atoms in these polyaromatic units, we use the following equation from (Jones 2012b),

$\left.N_{\mathrm{C}}=2 * N_{\mathrm{R}}+3.5 * \sqrt{(} N_{\mathrm{R}}\right)+0.5$.

As shown in Fig. 13, the polyaromatic units in our soot samples contain between 20 and 100 carbon atoms. These are in the same range as those discussed in Steglich et al. (2010), who proposed, in accordance with semi-empirical calculations, that a distribution of large PAH molecules with a mean size of 50-60 carbon atoms can produce a bump centered at $\sim 217.5 \mathrm{~nm}$.

\section{Discussion}

The transmission measurements from the VUV to the midinfrared of several carbonaceous samples have allowed us to 


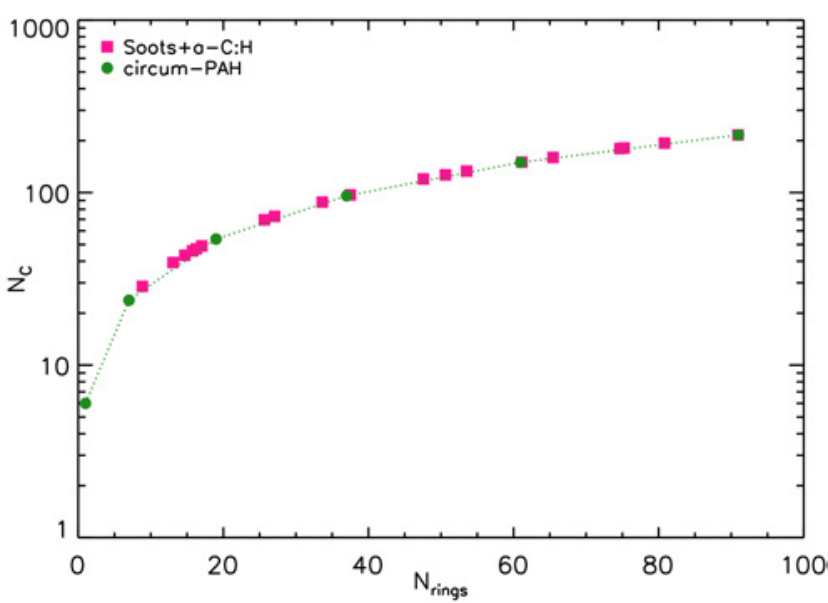

Fig. 13. Number of carbon atoms $\left(N_{\mathrm{C}}\right)$ versus the number of rings $N_{\mathrm{R}}$ in the polyaromatic units of the laboratory samples presented here (soots and a-C:H) and circum-PAHs, using Eq. (9).

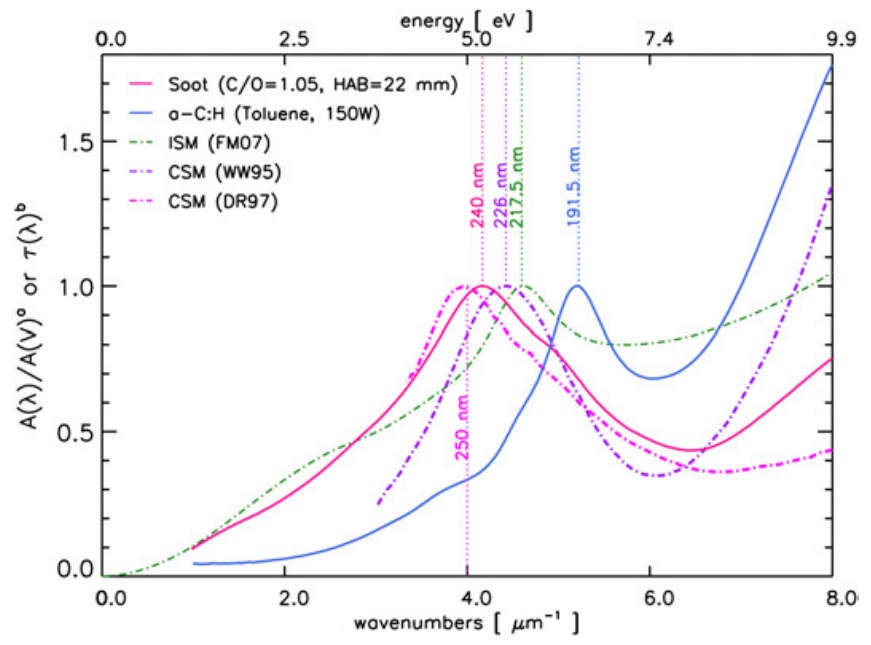

Fig. 14. Normalized laboratory soot and a-C:H visible-VUV spectra compared to the average ISM extinction curve (Fitzpatrick \& Massa 2007, FM07), and the CSM extinction curves of the circumstellar envelope of HD 213985 (Waelkens et al. 1995, WW95) and V348 Sagittarii (Drilling et al. 1997, DR97), for which the original spectrum has been heavily filtered. All spectra are re-normalized to the maximum intensity of their $\pi-\pi^{*}$ resonance.

perform a large spectroscopic study covering the main electronic and vibrational transitions. We find the following correlations:

- The position of the UV L1 feature $\left(\pi-\pi^{*}\right)$ is correlated to the position of the $\mathrm{sp}^{3}$ carbon defect, and to the position of the aromatic $\mathrm{C}=\mathrm{C}$ stretching mode. This reveals a relation between electronic and vibrational band positions in soots.

- The Tauc optical gap, $E_{\mathrm{g}}$, is correlated to the position of the $\pi-\pi^{*}$ band, $\omega_{\mathrm{c}}(\mathrm{L} 1)$. Both $E_{\mathrm{g}}$ and $\omega_{\mathrm{c}}(\mathrm{L} 1)$ are relevant parameters allowing the classification of both soots and a-C:Hs.

- The H/C ratio of these carbonaceous samples is correlated to $E_{\mathrm{g}}$ and therefore to $\omega_{\mathrm{c}}(\mathrm{L} 1)$. For soots, the empirical relationship between the $\mathrm{H} / \mathrm{C}$ ratio and the gap differs from that found for highly hydrogenated carbonaceous materials.

The wide variety of our laboratory carbonaceous dust allows us to explore the spectral properties of the observed ISM and CSM extinction curves (e.g., Fig. 14), from the VUV to the IR:

- Spectroscopy in the VUV $(120<\lambda<200 \mathrm{~nm})$ has allowed us to identify an absorption band in the VUV present in all our samples: the G3 band, with a fitted position centered at $\sim 9 \mu \mathrm{m}^{-1}(\sim 110 \mathrm{~nm})$ and an integrated optical depth ratio of approximately two with respect to L1. G3 is attributed to $\sigma-\sigma^{*}$ transitions and may contribute to the FUV rise identified in Fitzpatrick \& Massa (2007).

- For the average ISM bump, centered at $217.5 \mathrm{~nm}$, we infer the following spectral properties of the carrier: $E_{\mathrm{g}} \sim 1.2 \mathrm{eV}$, $\omega_{\mathrm{c}}(\mathrm{G} 3) \sim 9.5 \mu \mathrm{m}^{-1}, \omega_{\mathrm{c}}\left(\mathrm{sp}^{3}\right.$ defect $) \sim 1280 \mathrm{~cm}^{-1}, \omega_{\mathrm{c}}(\mathrm{C}=\mathrm{C}) \sim$ $1600 \mathrm{~cm}^{-1}$.

- For the average CSM bump, centered 226-250 nm, we infer the following spectral properties of the carrier: $E_{\mathrm{g}} \sim 0.7 \mathrm{eV}$, $\omega_{\mathrm{c}}(\mathrm{G} 3) \sim 9 \mu \mathrm{m}^{-1}, \omega_{\mathrm{c}}\left(\mathrm{sp}^{3}\right.$ defect $) \sim 1250 \mathrm{~cm}^{-1}, \omega_{\mathrm{c}}(\mathrm{C}=\mathrm{C}) \sim$ $1592 \mathrm{~cm}^{-1}$.

The connection between ultraviolet extinction data and infrared emission has been possible thanks to early datasets from the IUE and the Infrared Astronomical Satellite (IRAS), observing towards the same lines of sight. Cox \& Leene (1987) showed the absence of correlation between the mid-infrared excess and the normalized intensity of the UV bump, but later work by Cardelli et al. (1989) showed that their bump normalization was not appropriate. An extended study by Jenniskens \& Desert (1993) and later on by Boulanger et al. (1994) revealed a link between mid-infrared emission bands (AIBs) and the UV bump absorption. In contrast, they found no relation between the AIBs and the FUV rise.

Correlations between the positions of UV and infrared absorption bands are found for the carbonaceous samples presented in this paper. These spectral parameters suggest that the carrier of the ISM bump is likely found at the frontier of class B/A of the AIBs, while the carrier of the CSM bump is found at the frontier of class B/C. Based on the Tauc optical gap and using available empirical formulae for carbons, the structure of the ISM UV bump carrier implies an average polyaromatic unit size $\sim 0.7 \mathrm{~nm}$ and for the CSM UV bump carrier, $\sim 1.1 \mathrm{~nm}$, within nanoparticles.

While the position of the interstellar $217.5 \mathrm{~nm}$ bump $\left(4.592 \mu \mathrm{m}^{-1}\right)$ is stable, its FWHM varies (Fitzpatrick \& Massa 2005). The FWHM of the $\pi-\pi^{*}$ band of our carbonaceous analogs, $\gamma(\mathrm{L} 1)$, is correlated to the position $\omega_{\mathrm{c}}(\mathrm{L} 1)$. None of our samples fulfill simultaneously the observed constraints on the UV bump (position, FWHM) in interstellar spectra (Fitzpatrick \& Massa 2007). In Fig. 15, we take the average interstellar extinction curve and perform a deconvolution as done for our laboratory samples to explore the effect of the deconvolution on the same basis. A direct comparison of the FWHM of a laboratory soot $\left(1.88 \mu \mathrm{m}^{-1}\right)$ to the newly parametrized FWHM $\left(1.78 \mu \mathrm{m}^{-1}\right)$ from the average interstellar extinction curve indicates that laboratory polyaromatic solid carbons can approximate the average carrier of the UV bump. However, it is more likely than more than one kind of carbon is measured towards a line of sight, and that more hydrogenated carbons contribute strongly to the FUV rise as shown in Gavilan et al. (2016) and in Fig. 14, where our laboratory soot and a-C:H spectra are compared to extinction curves in the ISM and CSM.

\section{Conclusions}

We have produced laboratory analogs to interstellar carbonaceous dust characterized by their wide degree of hydrogenation and differences in polyaromatic structure. This influences the spectral signatures, in particular the position of the UV bump, attributed to $\pi-\pi^{*}$ electronic transitions. Our carbonaceous analogs 


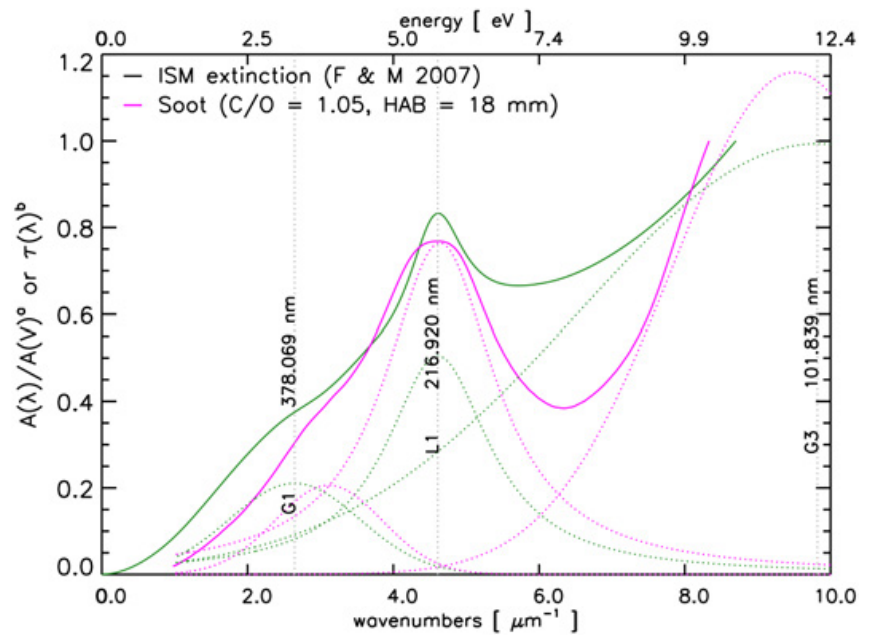

Fig. 15. Deconvolution of the average interstellar extinction curve (Fitzpatrick \& Massa 2007) ( ${ }^{a}$ normalized to its maximum) following the deconvolution procedure of laboratory soots described in Sect. 3.1. The $\mathrm{L} 1$ peak is centered at $\omega_{\mathrm{c}}=4.609 \mu \mathrm{m}^{-1}$ with a $F W H M=$ $1.779 \mu \mathrm{m}^{-1}$. While the position is unchanged with respect to the parametrization of Fitzpatrick \& Massa (2007), the original FWHM value is almost doubled. For comparison, the spectra of a laboratory soot prepared in a flame with $\mathrm{C} / \mathrm{O}=1.05$ and $\mathrm{HAB}=18 \mathrm{~mm}$ is included, showing a similarly intense and wide $\pi-\pi^{*}$ transition, a G1 peak, and a slightly less intense FUV rise.

consist of soots, characterized by low $\mathrm{H} / \mathrm{C}$ and $E_{\mathrm{g}}$ values. A hydrogenated a-C:H with $E_{\mathrm{g}} \sim 2 \mathrm{eV}$ was also produced. The $\mathrm{UV}$ to mid-infrared spectroscopy has allowed us to find correlations between the electronic transitions and vibrational modes and to deduce structural properties such as the average length $(\sim 0.7-$ $1.1 \mathrm{~nm}$ ) of polyaromatic units within nanoparticles.

These laboratory correlations suggest that for the interstellar and circumstellar UV bump carriers, infrared signatures are expected in classes $\mathrm{B} / \mathrm{A}$ and $\mathrm{B} / \mathrm{C}$ of the $\mathrm{AIBs}$ respectively. More hydrogenated carbons contribute to the FUV rise in agreement with its weak correlation with the UV bump. Observations are then not only sensitive to local environmental conditions but also to the transition of dust from circum- to interstellar environments. As shown by our measurements, disordered polyaromatic carbonaceous grains are viable carriers of the observed UV interstellar and circumstellar extinction.

Acknowledgements. VUV measurements were performed at the DISCO beamline of the SOLEIL synchrotron (projects: $20141074 \&$ 20130778). This work has been supported by the French program PCMI, and the ANR COSMISME project (grant ANR-2010-BLAN-0502). K.C.L. thanks the Vietnamese government for a doctoral scholarship. L.G. thanks the Centre National d'Études Spatiales (CNES) for a post-doctoral fellowship.

\section{References}

Acke, B., Bouwman, J., Juhász, A., et al. 2010, ApJ, 718, 558 Adkins, E. M., \& Miller, J. H. 2015, Phys. Chem. Chem. Phys., 17, 2686

Alata, I., Cruz-Diaz, G. A., Muñoz Caro, G. M., \& Dartois, E. 2014, A\&A, 569 A119

Alata, I., Jallat, A., Gavilan, L., et al. 2015, A\&A, 584, A123

Allamandola, L. J., Tielens, A. G. G. M., \& Barker, J. R. 1985, ApJ, 290, L25 Allamandola, L. J., Tielens, A. G. G. M., \& Barker, J. R. 1989, ApJS, 71, 733 Bescond, A., Yon, J., Ouf, F.-X., et al. 2016, J. Aerosol Sci., 101, 118

Blanco, A., Fonti, S., \& Orofino, V. 1995, ApJ, 448, 339

Boulanger, F., Prevot, M. L., \& Gry, C. 1994, A\&A, 284, 956

Cardelli, J. A., Clayton, G. C., \& Mathis, J. S. 1989, ApJ, 345, 245

Carpentier, Y., Féraud, G., Dartois, E., et al. 2012, A\&A, 548, A40

Colangeli, L., Mennella, V., Blanco, A., et al. 1993, ApJ, 418, 435

Colangeli, L., Bussoletti, E., Pestellini, C. C., et al. 1997, Adv. Space Res., 20, 1617

Cox, P., \& Leene, A. 1987, A\&A, 174, 203
Dartois, E., Muñoz Caro, G. M., Deboffle, D., \& d'Hendecourt, L. 2004, A\&A, 423, L33

Dartois, E., Muñoz Caro, G. M., Deboffle, D., Montagnac, G., \& D’Hendecourt, L. 2005, A\&A, 432, 895

Dartois, E., Geballe, T. R., Pino, T., et al. 2007, A\&A, 463, 635

Draine, B. T., \& Lee, H. M. 1984, ApJ, 285, 89

Drilling, J. S., Hecht, J. H., Clayton, G. C., et al. 1997, ApJ, 476, 865

Duley, W. W., \& Hu, A. 2012, ApJ, 761, 115

Duley, W. W., \& Whittet, D. C. B. 1992, MNRAS, 255, 243

Dworschak, W. 1990, Thin Solid Films, 189, 257

Fink, J., Müller-Heinzerling, T., Pflüger, J., et al. 1984, Phys. Rev. B, 30, 4713

Fitzpatrick, E. L., \& Massa, D. 1986, ApJ, 307, 286

Fitzpatrick, E. L., \& Massa, D. 1988, ApJ, 328, 734

Fitzpatrick, E. L., \& Massa, D. 1990, ApJS, 72, 163

Fitzpatrick, E. L., \& Massa, D. 2005, AJ, 130, 1127

Fitzpatrick, E. L., \& Massa, D. 2007, ApJ, 663, 320

Furton, D. G., Laiho, J. W., \& Witt, A. N. 1999, ApJ, 526, 752

Gadallah, K. A. K., Mutschke, H., \& Jäger, C. 2011, A\&A, 528, A56

Gavilan, L., Alata, I., Le, K. C., et al. 2016, A\&A, 586, A106

Giuliani, A., Jamme, F., Rouam, V., et al. 2009, J. Synchrotron Radiation, 16, 835

Godard, M., \& Dartois, E. 2010, A\&A, 519, A39

Godard, M., Féraud, G., Chabot, M., et al. 2011, A\&A, 529, A146

Greenberg, J. M., \& Li, A. 1999, Adv. Space Res., 24, 497

Jäger, C., Krasnokutski, S., Staicu, A., et al. 2006, ApJS, 166, 557

Jäger, C., Mutschke, H., Henning, T., \& Huisken, F. 2008, ApJ, 689, 249

Jenniskens, P., \& Desert, F. X. 1993, A\&A, 275, 549

Joblin, C., D'Hendecourt, L., Leger, A., \& Defourneau, D. 1994, A\&A, 281, 923

Jones, A. P. 1990, MNRAS, 247, 305

Jones, A. P. 2012a, A\&A, 545, C2

Jones, A. P. 2012b, A\&A, 540, A1

Jones, A. P. 2012c, A\&A, 542, A98

Jones, A. P., Fanciullo, L., Köhler, M., et al. 2013, A\&A, 558, A62

Leger, A., \& Puget, J. L. 1984, A\&A, 137, L5

Llamas Jansa, I., Jäger, C., Mutschke, H., \& Henning, T. 2003, in Astrophysics of Dust, ed. A. N. Witt

Mansurov, Z. A. 2005, Combustion, Explosion and Shock Waves, 41, 727

Markwardt, C. B. 2009, Proc. Astronomical Data Analysis Software and Systems XVIII, 411, 251

Mennella, V., Colangeli, L., Palumbo, P., et al. 1996, ApJ, 464, L191

Mennella, V., Brucato, J. R., Colangeli, L., \& Palumbo, P. 2002, ApJ, 569, 531

Mennella, V., Baratta, G. A., Esposito, A., Ferini, G., \& Pendleton, Y. J. 2003, ApJ, 587, 727

Peeters, E. 2014, in The Diffuse Interstellar Bands, eds. J. Cami, \& N. L. J. Cox, IAU Symp., 297, 187

Peeters, E., Hony, S., Van Kerckhoven, C., et al. 2002, A\&A, 390, 1089

Pendleton, Y. J., \& Allamandola, L. J. 2002, ApJS, 138, 75

Pino, T., Dartois, E., Cao, A.-T., et al. 2008, A\&A, 490, 665

Pino, T., Carpentier, Y., Féraud, G., et al. 2015, Highlights of Astronomy, 16, 717

Puget, J. L., \& Leger, A. 1989, ARA\&A, 27, 161

Puget, J. L., Leger, A., \& Boulanger, F. 1985, A\&A, 142, L19

Robertson, J. 1986, Adv. Phys., 35, 317

Robertson, J. 1991, J. Non Crystalline Solids, 137, 825

Robertson, J., \& O’Reilly, E. P. 1987, Phys. Rev. B, 35, 2946

Rosenberg, M. J. F., Berné, O., \& Boersma, C. 2014, A\&A, 566, L4

Russo, C., Stanzione, F., Tregrossi, A., \& Ciajolo, A. 2014, Carbon, 74, 127

Schnaiter, M., Mutschke, H., Dorschner, J., Henning, T., \& Salama, F. 1998, ApJ, 498, 486

Scott, A., \& Duley, W. W. 1996, ApJ, 472, L123

Silva, S. R. P., Robertson, J., Milne, W. I., \& Amaratunga, G. A. J., 1998, Amorphous Carbon: State of the Art, Proc. 1st Int. Specialist Meeting on Amorphous Carbon (smac '97) (World Scientific Publishing Co. Pte. Ltd.)

Sloan, G. C., Jura, M., Duley, W. W., et al. 2007, ApJ, 664, 1144

Stecher, T. P., \& Donn, B. 1965, ApJ, 142, 1681

Steglich, M., Jäger, C., Rouillé, G., et al. 2010, ApJ, 712, L16

Tamor, M. A., \& Wu, C. H. 1990, J. Appl. Phys., 67, 1007

Tauc, J., Grigorovici, R., \& Vancu, A. 1966, Phys. Status Solid B-basic Solid State Physics, 15, 627

Trumpler, R. J. 1930, PASP, 42, 267

Violi, A., Sarofim, A. F., \& Truong, T. N. 2002, Combustion Science and Technology, 174, 205

Waelkens, C., Waters, L. B. F. M., van Winckel, H., \& Daems, K. 1995, Ap\&SS, 224, 357

Yang, X. J., Glaser, R., Li, A., \& Zhong, J. X. 2013, ApJ, 776, 110

Zubko, V. G., Mennella, V., Colangeli, L., \& Bussoletti, E. 1996, MNRAS, 282, 1321 


\section{Appendix A}

Here we provide the additional Figures and Tables that are referenced in the main body of the text. These are organized as VUV spectra $\left(1-10 \mu \mathrm{m}^{-1}\right)$, and the mid-infrared spectra of the $3.4 \mu \mathrm{m}$ band region and the 5-20 $\mu \mathrm{m}$ band region.

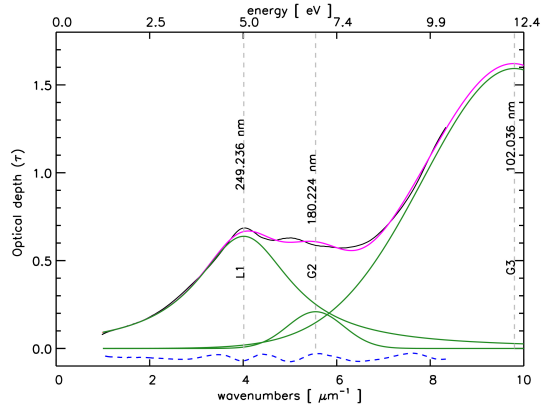

(a) $20 \mathrm{~mm}$

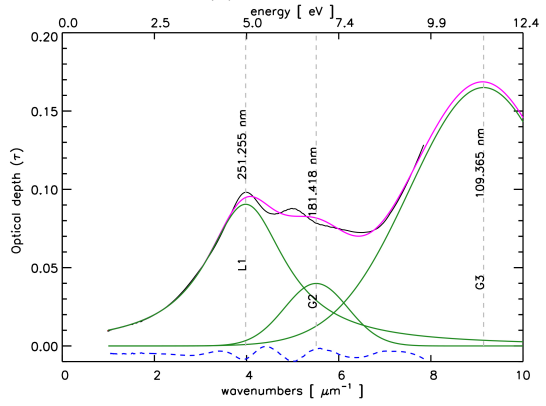

(d) $21 \mathrm{~mm}$

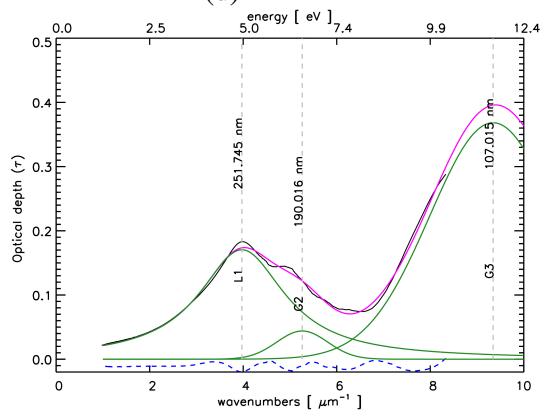

(g) $22 \mathrm{~mm}$

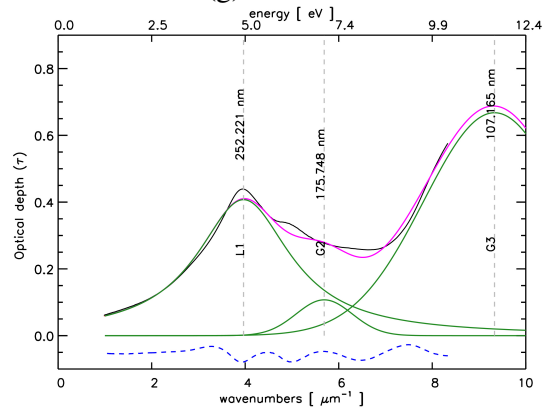

(j) $30 \mathrm{~mm}$

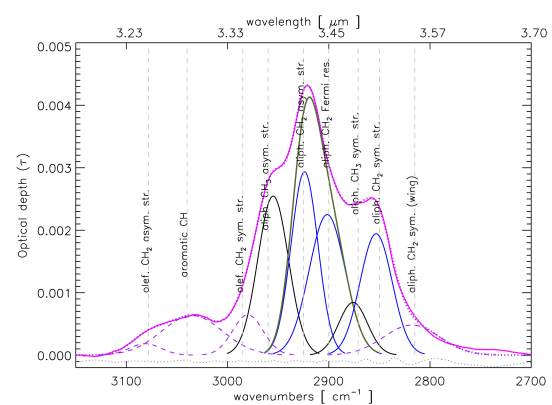

(b) $20 \mathrm{~mm}$

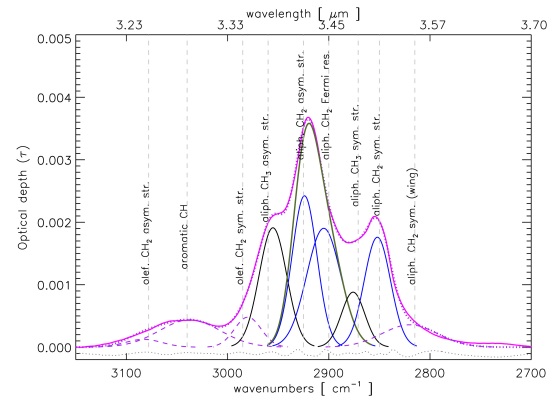

(e) $21 \mathrm{~mm}$

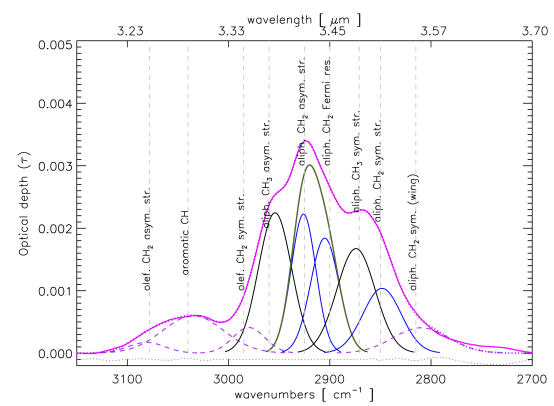

(h) $22 \mathrm{~mm}$

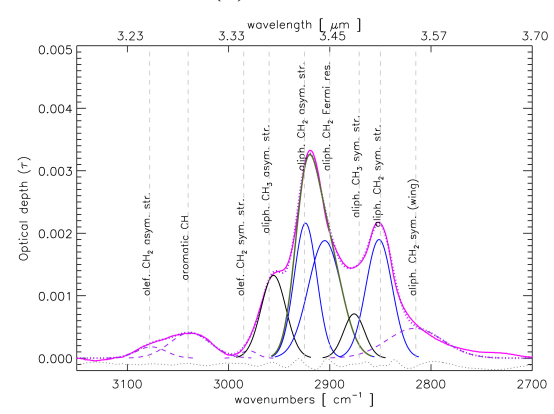

(k) $30 \mathrm{~mm}$

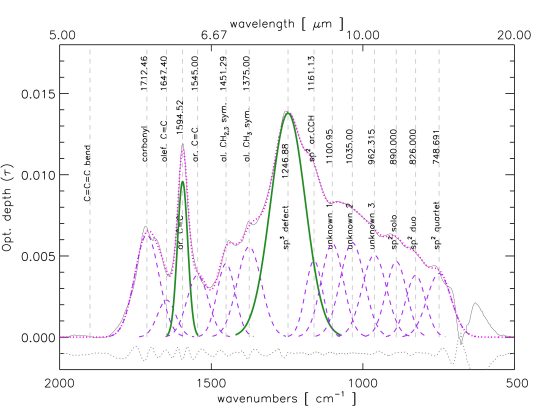

(c) $20 \mathrm{~mm}$

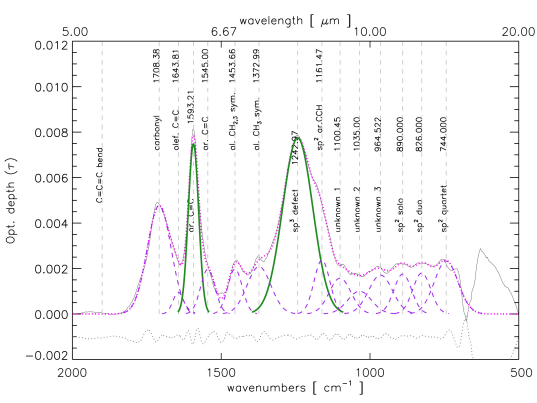

(f) $21 \mathrm{~mm}$

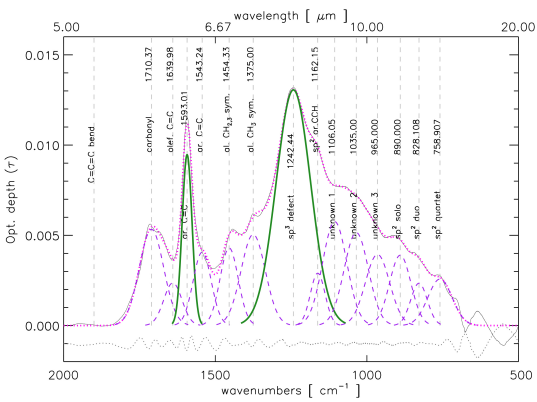

(i) $22 \mathrm{~mm}$

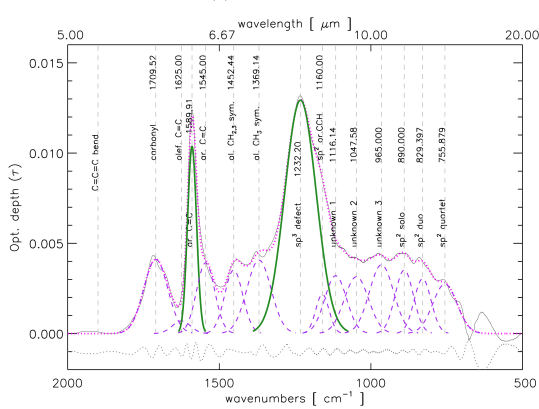

(1) $30 \mathrm{~mm}$

Fig. A.1. UV-VUV and mid-infrared spectral deconvolution for soot samples prepared with a $\mathrm{C} / \mathrm{O}=0.82$ combustion flame, retrieved at a $\mathrm{HAB}$ of a) $20 \mathrm{~mm}$ to $l) 30 \mathrm{~mm}$. 


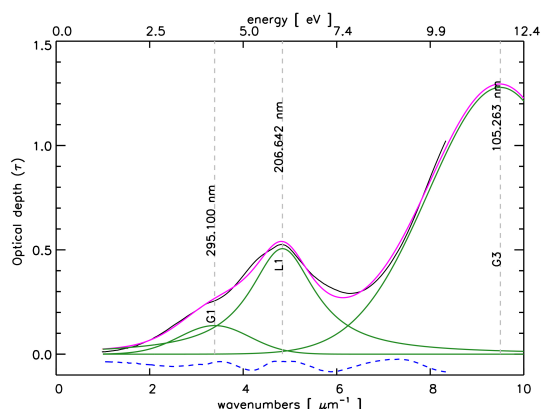

(a) $18 \mathrm{~mm}$

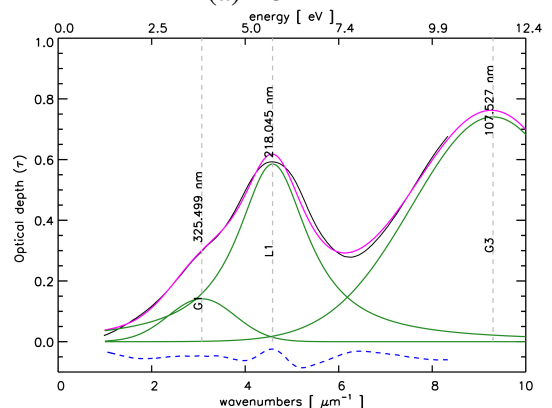

(d) $21 \mathrm{~mm}$

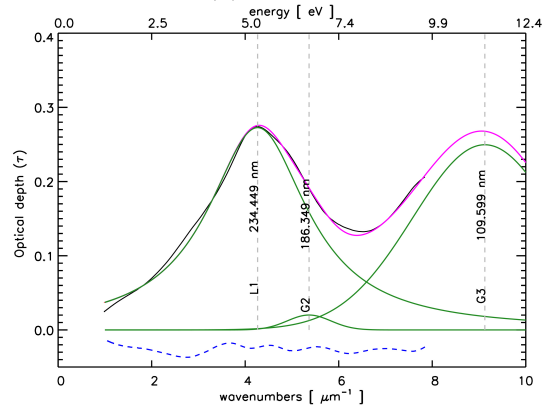

(g) $25 \mathrm{~mm}$

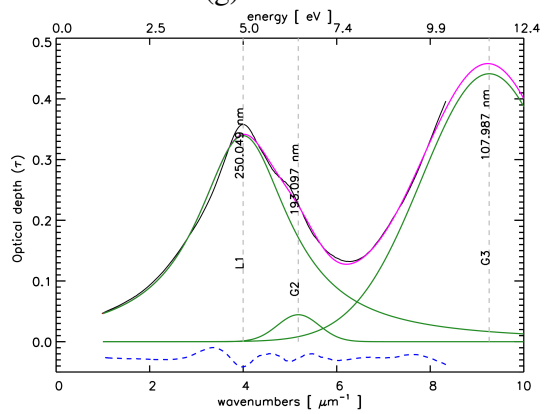

(j) $30 \mathrm{~mm}$

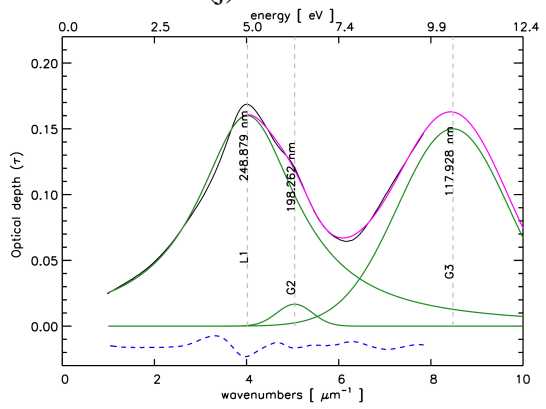

(m) $39 \mathrm{~mm}$

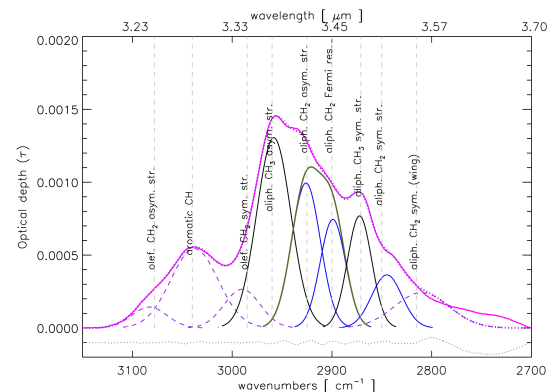

(b) $18 \mathrm{~mm}$

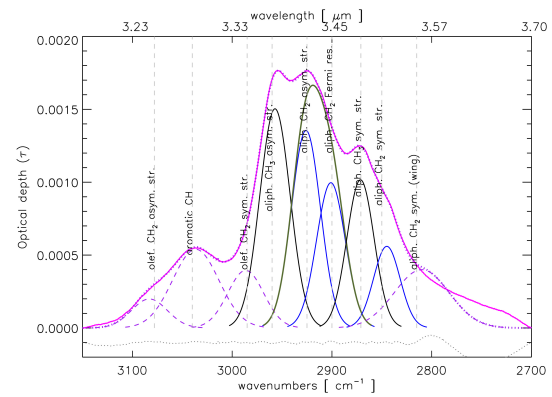

(e) $21 \mathrm{~mm}$

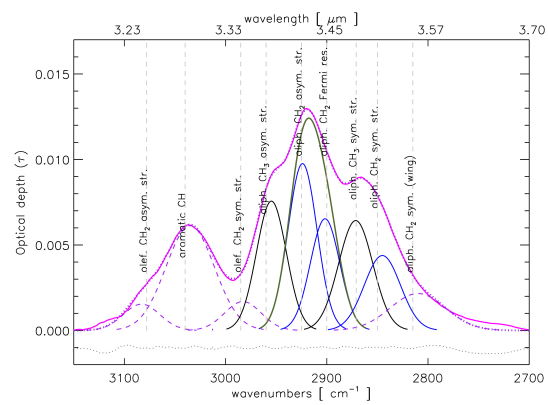

(h) $25 \mathrm{~mm}$

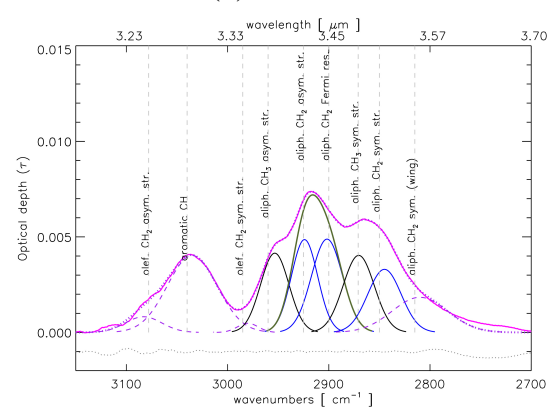

(k) $30 \mathrm{~mm}$

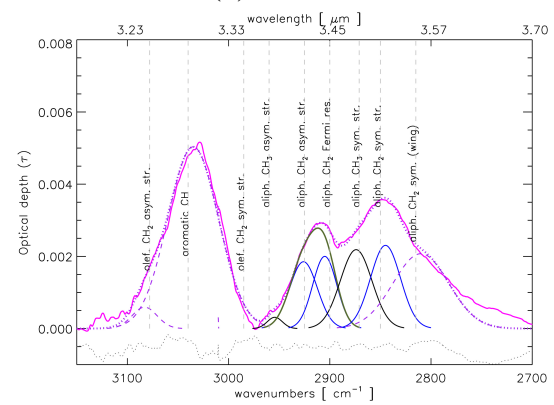

(n) $39 \mathrm{~mm}$

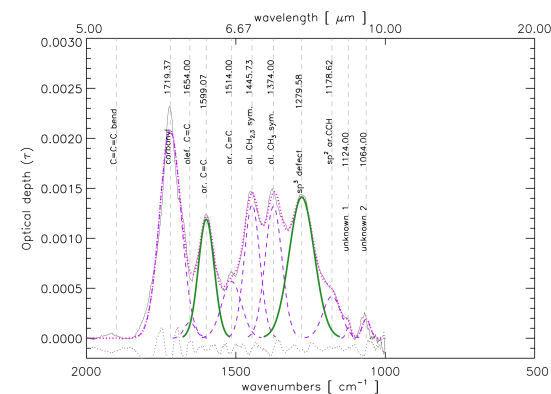

(c) $18 \mathrm{~mm}$

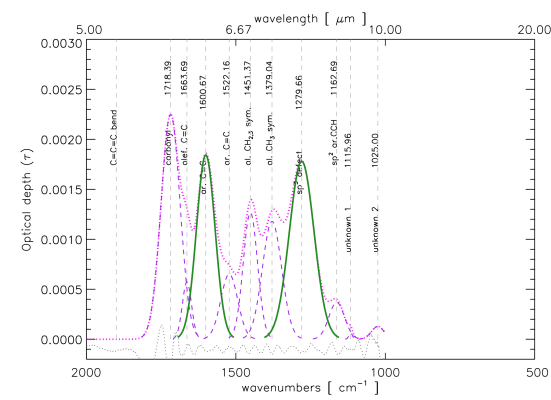

(f) $21 \mathrm{~mm}$

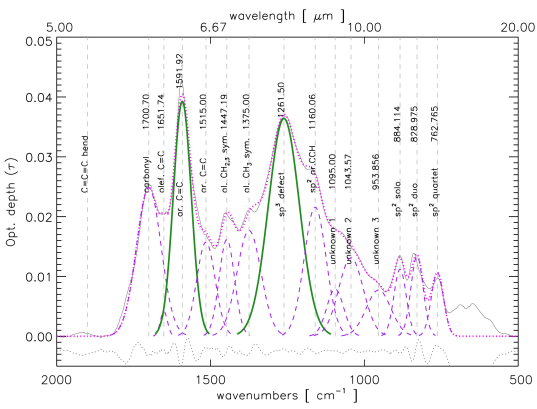

(i) $25 \mathrm{~mm}$

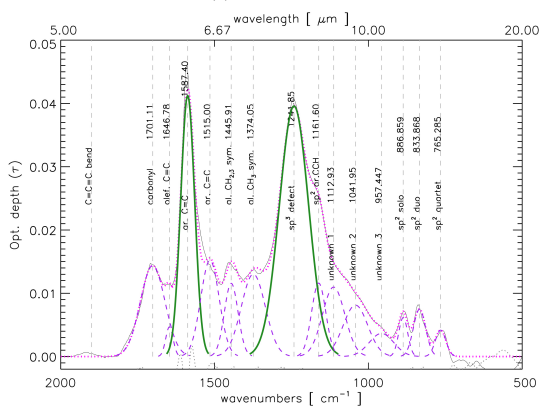

(1) $30 \mathrm{~mm}$

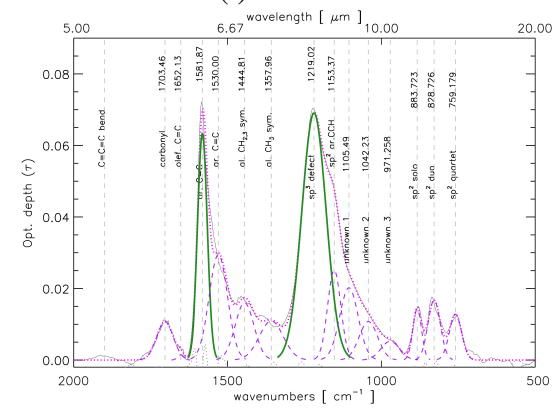

(o) $39 \mathrm{~mm}$

Fig. A.2. UV-VUV and mid-infrared spectral deconvolution for soot samples prepared with a $\mathrm{C} / \mathrm{O}=1$ combustion flame, retrieved at a $\mathrm{HAB}$ of a) $18 \mathrm{~mm}$ to $o) 39 \mathrm{~mm}$. 
L. Gavilan et al.: Polyaromatic disordered carbon grains as carriers of the UV bump

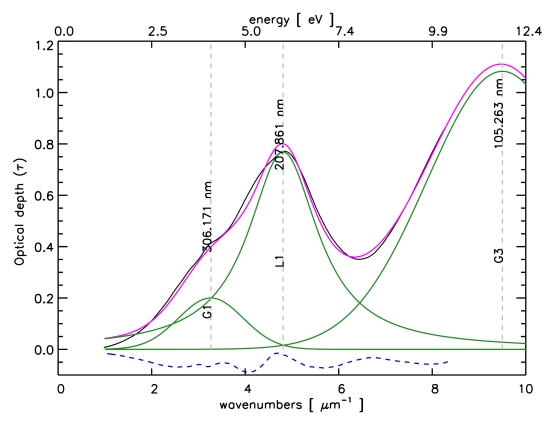

(a) $14 \mathrm{~mm}$

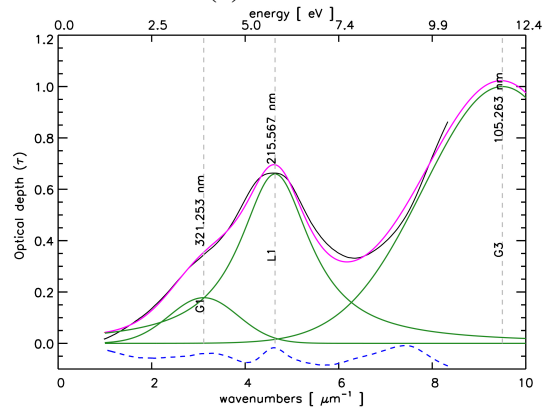

(d) $18 \mathrm{~mm}$

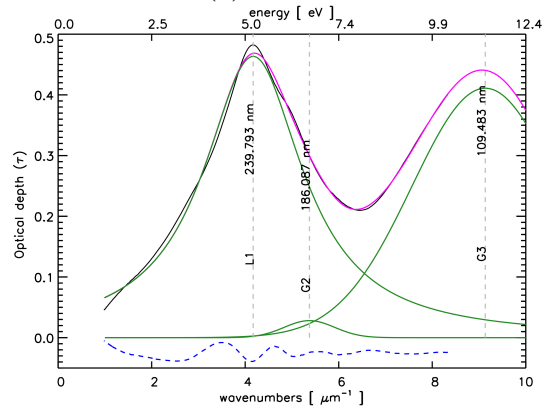

(g) $22 \mathrm{~mm}$

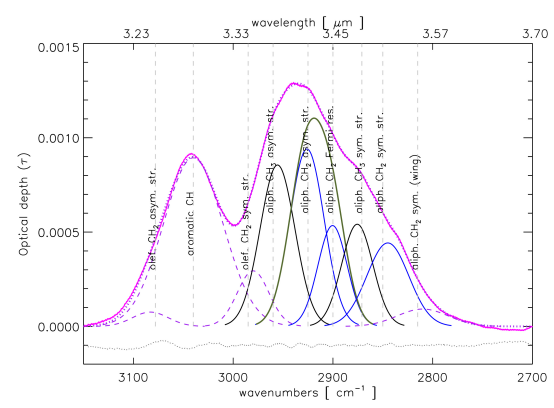

(b) $14 \mathrm{~mm}$

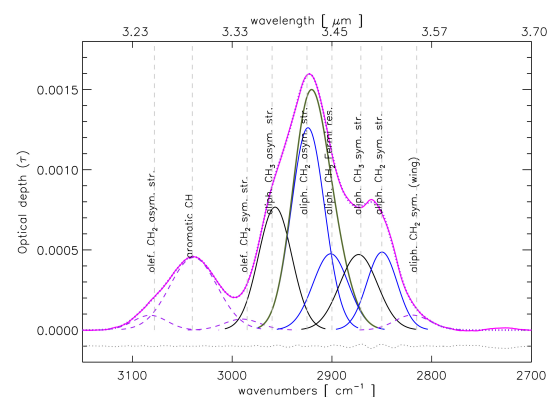

(e) $18 \mathrm{~mm}$

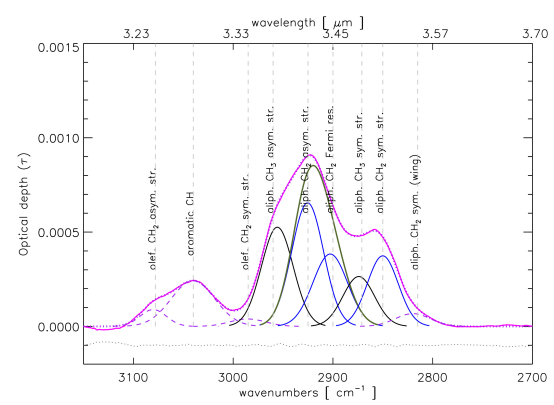

(h) $22 \mathrm{~mm}$

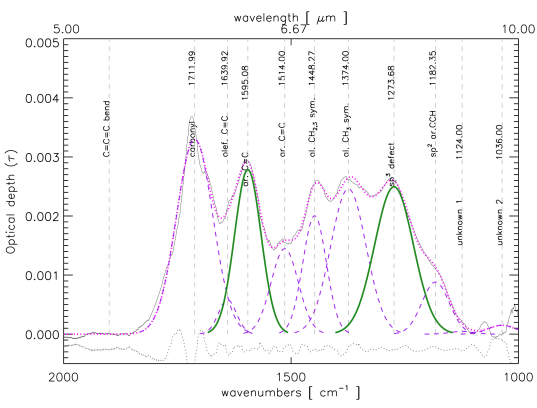

(c) $14 \mathrm{~mm}$

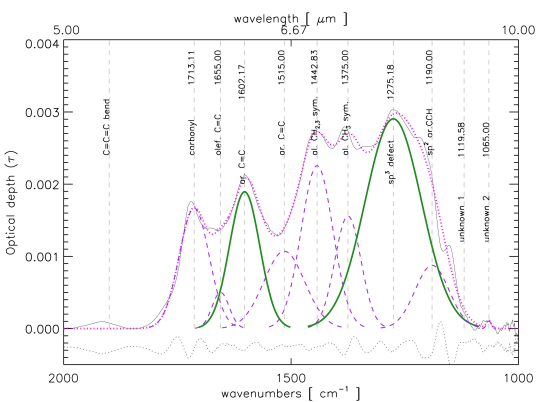

(f) $18 \mathrm{~mm}$

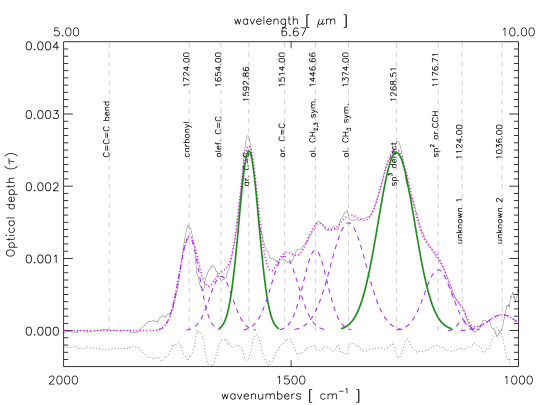

(i) $22 \mathrm{~mm}$

Fig. A.3. UV-VUV and mid-infrared spectral deconvolution for soot samples prepared with a $\mathrm{C} / \mathrm{O}=1.05$ combustion flame, retrieved at a $\mathrm{HAB}$ of a) $14 \mathrm{~mm}$ to $i) 22 \mathrm{~mm}$. 


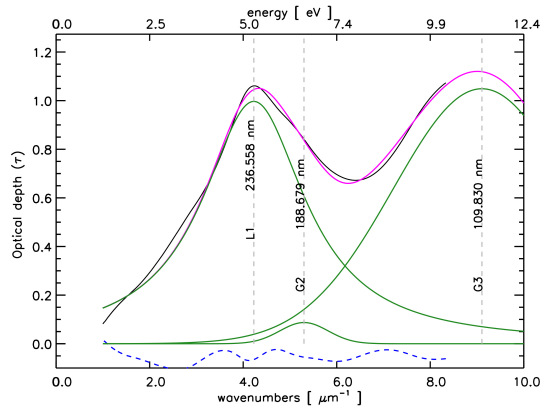

(a) $22 \mathrm{~mm}$

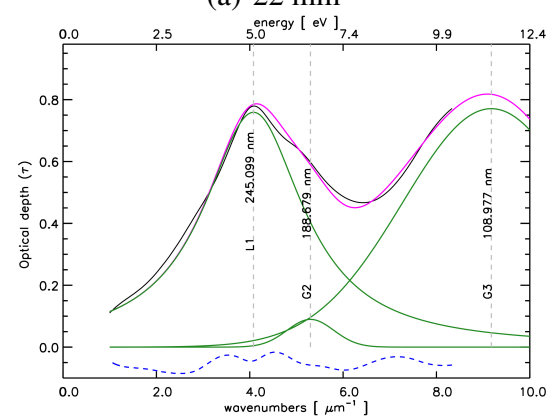

(d) $24 \mathrm{~mm}$

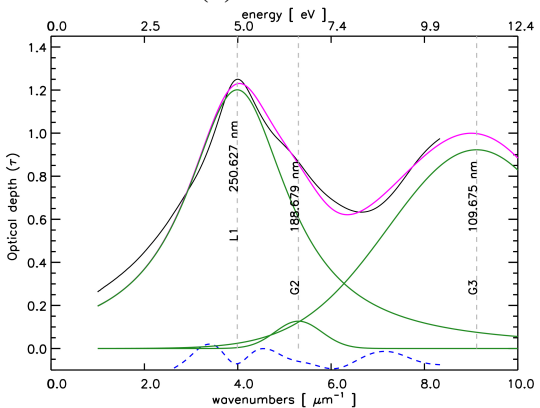

(g) $26 \mathrm{~mm}$

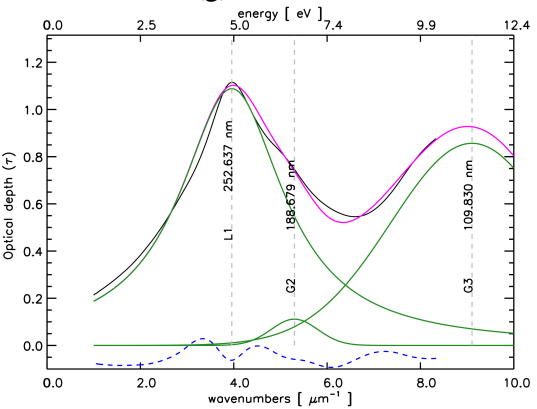

(j) $28 \mathrm{~mm}$

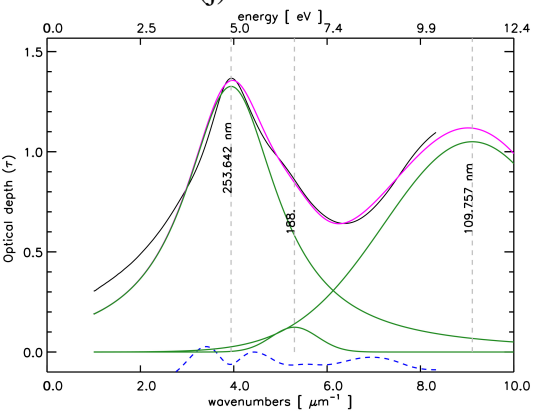

(m) $30 \mathrm{~mm}$

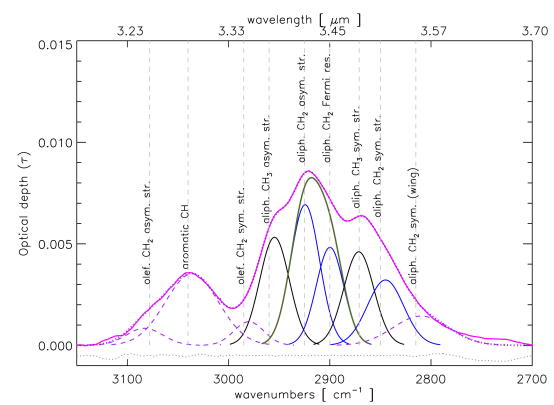

(b) $22 \mathrm{~mm}$

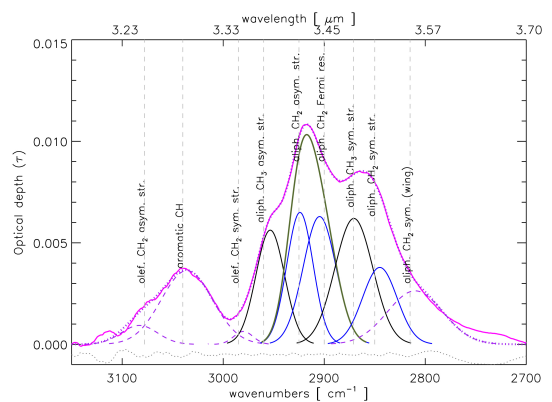

(e) $24 \mathrm{~mm}$

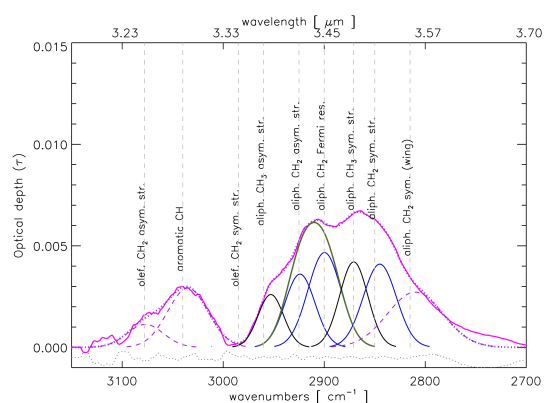

(h) $26 \mathrm{~mm}$

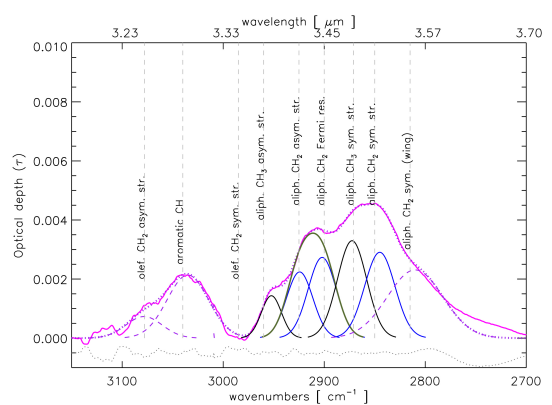

(k) $28 \mathrm{~mm}$

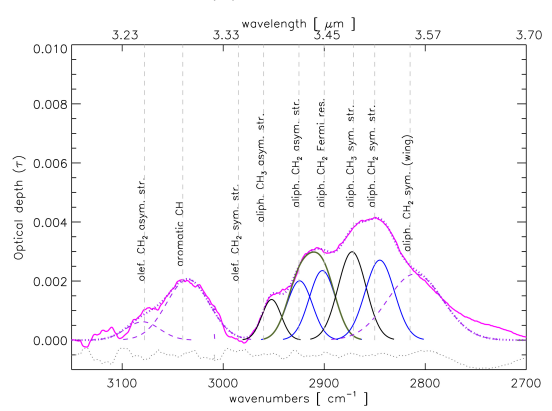

(n) $30 \mathrm{~mm}$

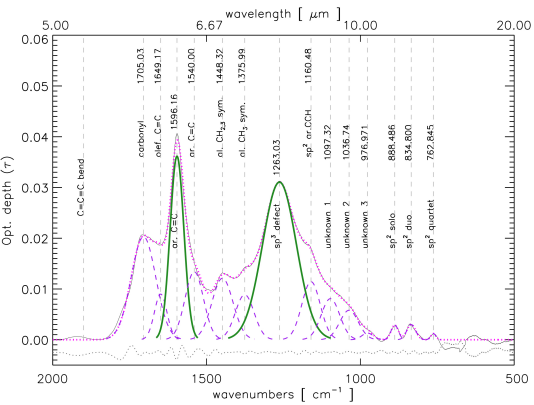

(c) $22 \mathrm{~mm}$

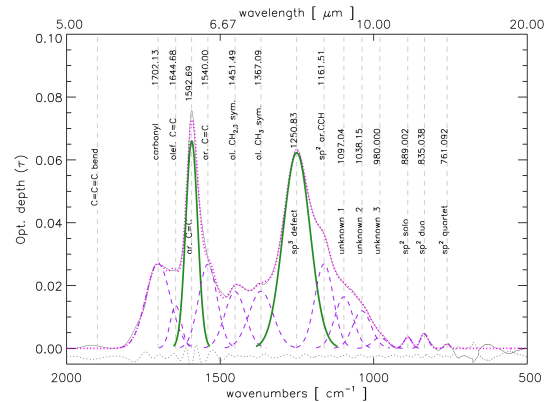

(f) $24 \mathrm{~mm}$

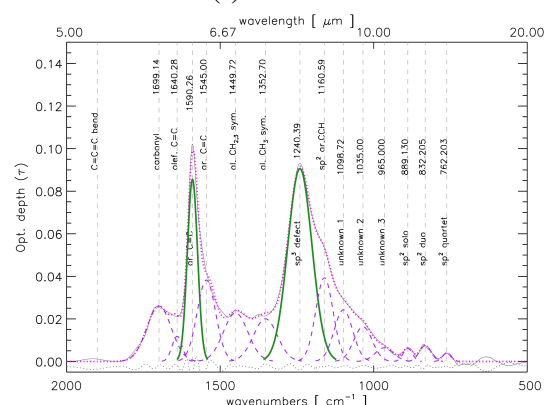

(i) $26 \mathrm{~mm}$

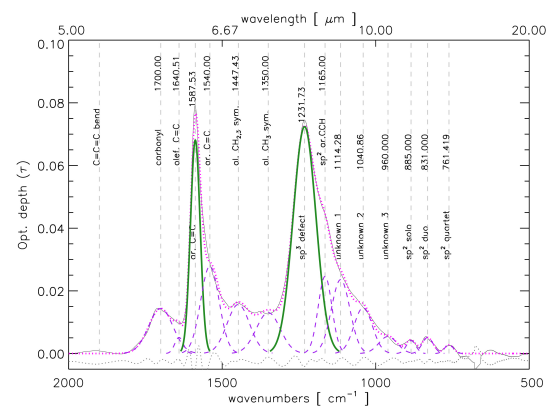

(1) $28 \mathrm{~mm}$

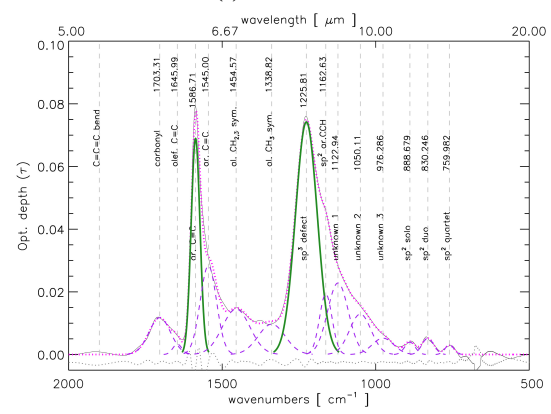

(o) $30 \mathrm{~mm}$

Fig. A.4. UV-VUV and mid-infrared spectral deconvolution for soot samples prepared with a $\mathrm{C} / \mathrm{O}=1.05$ combustion flame, retrieved at a $\mathrm{HAB}$ of a) $22 \mathrm{~mm}$ to $o) 30 \mathrm{~mm}$. 


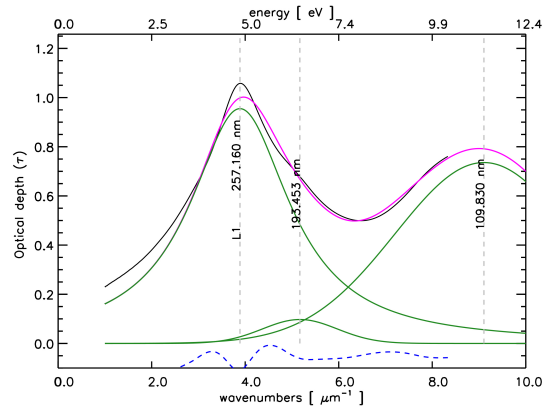

(a) $32 \mathrm{~mm}$

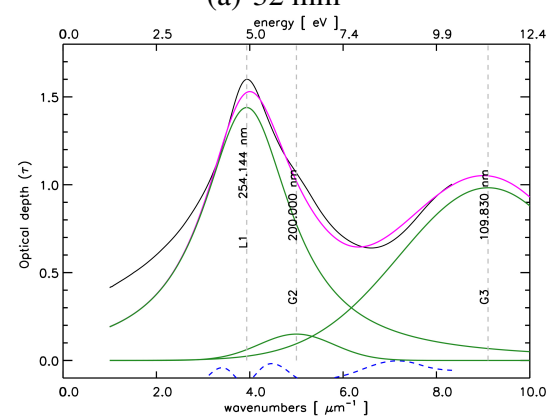

(d) $34 \mathrm{~mm}$

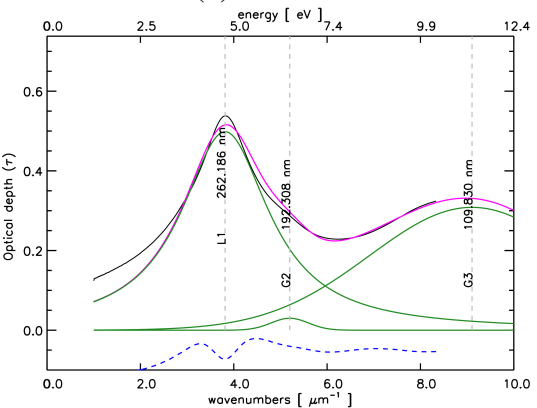

(g) $36 \mathrm{~mm}$

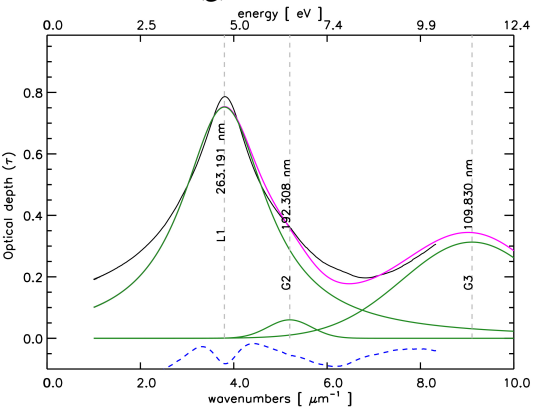

(j) $42 \mathrm{~mm}$

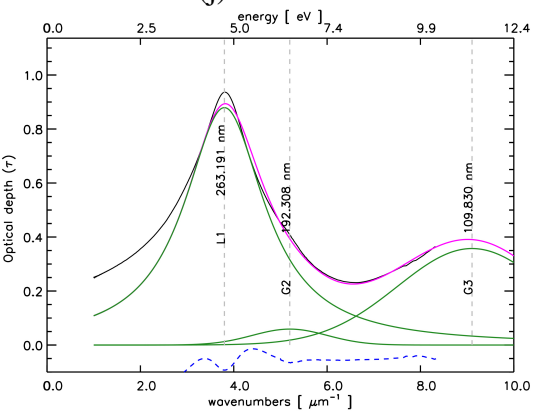

(m) $50 \mathrm{~mm}$

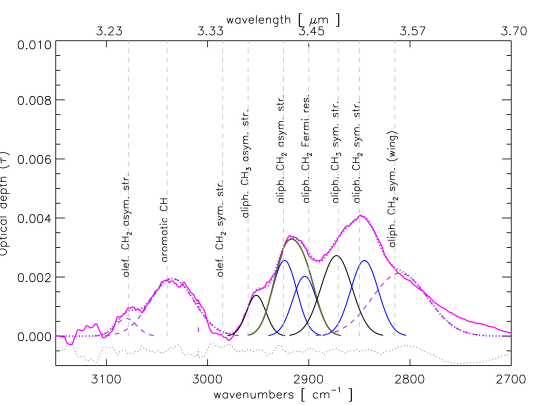

(b) $32 \mathrm{~mm}$

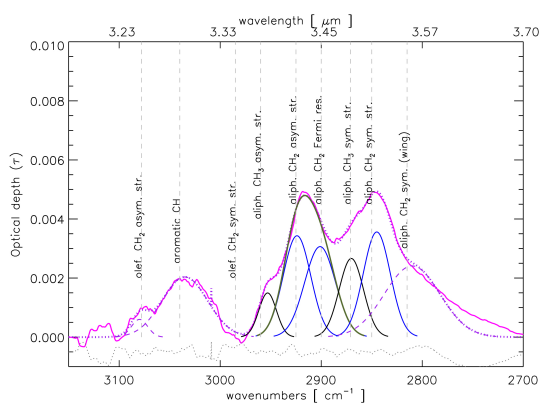

(e) $34 \mathrm{~mm}$

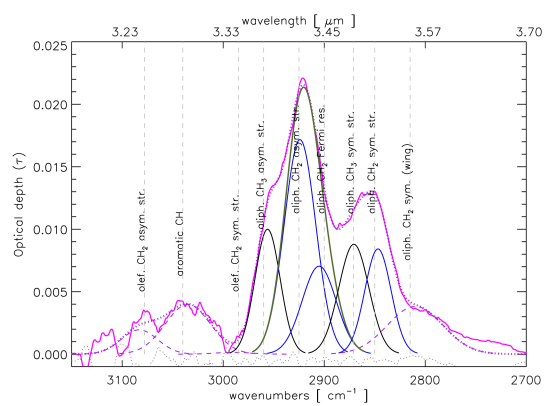

(h) $36 \mathrm{~mm}$

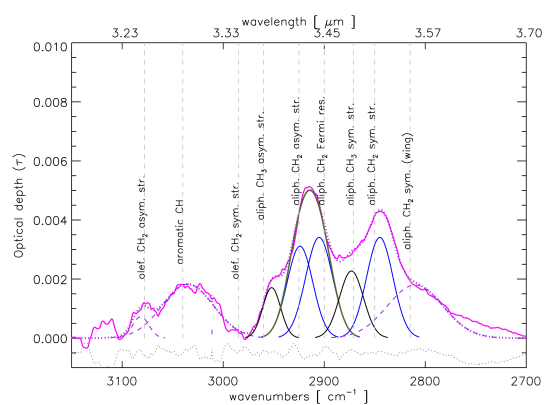

(k) $42 \mathrm{~mm}$

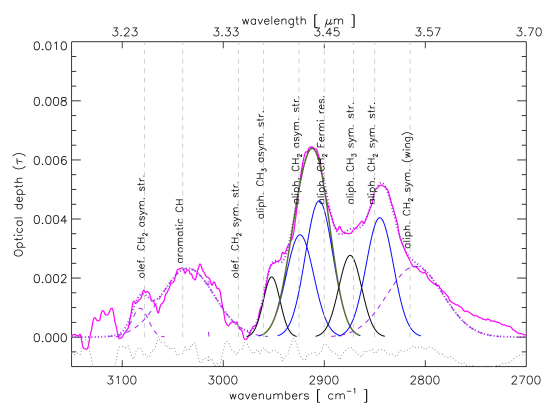

(n) $50 \mathrm{~mm}$

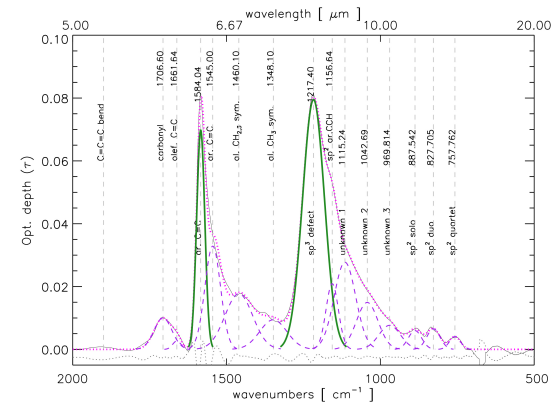

(c) $32 \mathrm{~mm}$

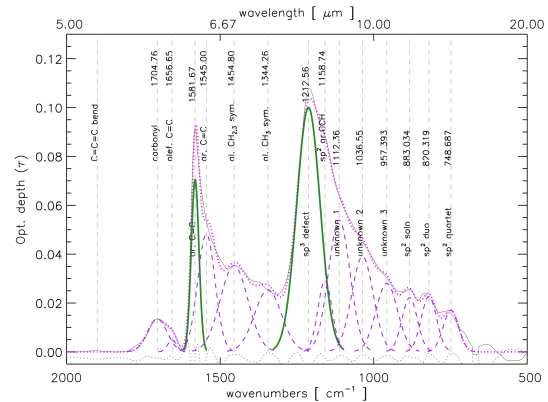

(f) $34 \mathrm{~mm}$

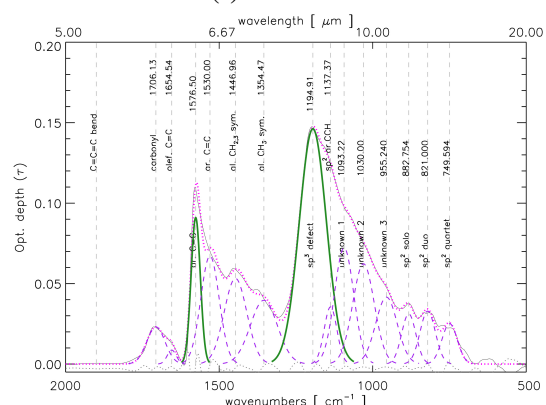

(i) $36 \mathrm{~mm}$

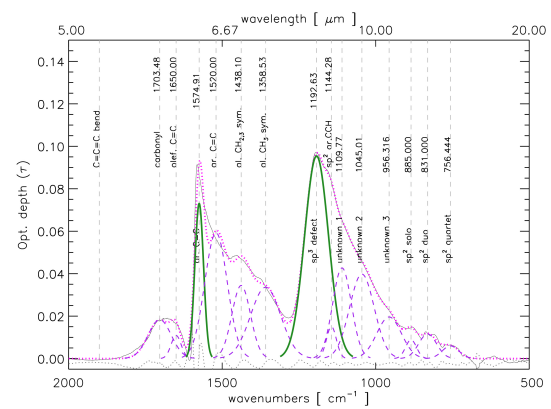

(1) $42 \mathrm{~mm}$

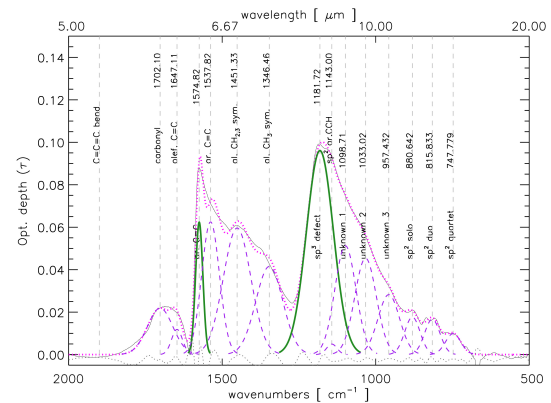

(o) $50 \mathrm{~mm}$

Fig. A.5. UV-VUV and mid-infrared spectral deconvolution for soot samples prepared with a $\mathrm{C} / \mathrm{O}=1.05$ combustion flame, retrieved at a $\mathrm{HAB}$ of a) $32 \mathrm{~mm}$ to $o) 50 \mathrm{~mm}$. 


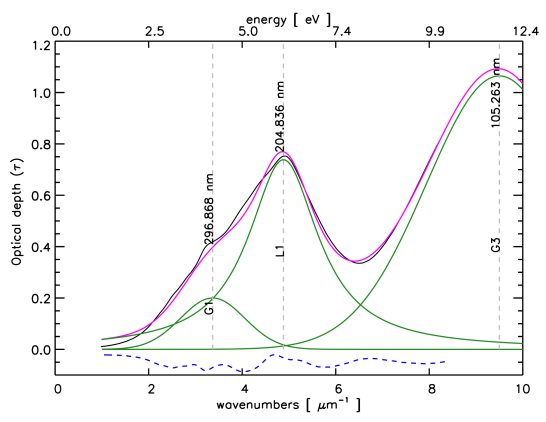

(a) $25 \mathrm{~mm}$

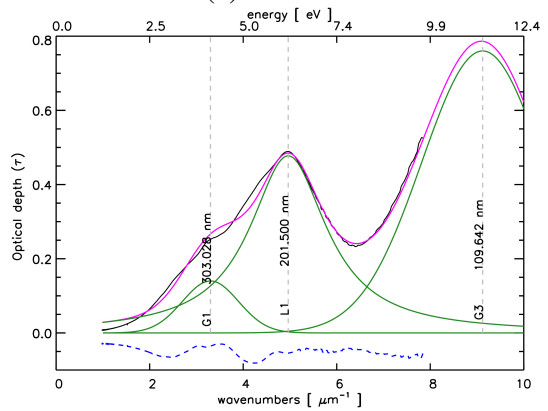

(d) $27 \mathrm{~mm}$

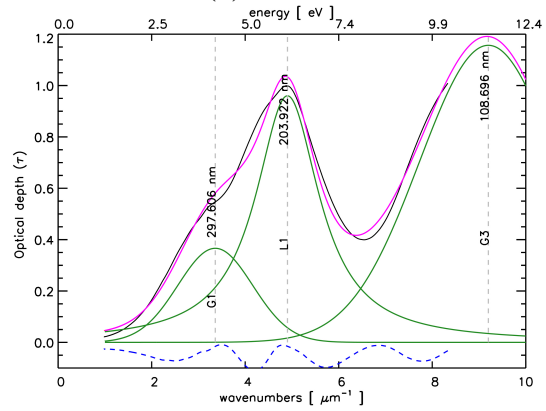

(g) $30 \mathrm{~mm}$

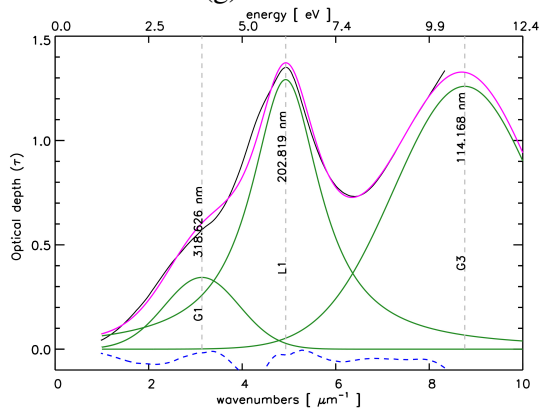

(j) $39 \mathrm{~mm}$

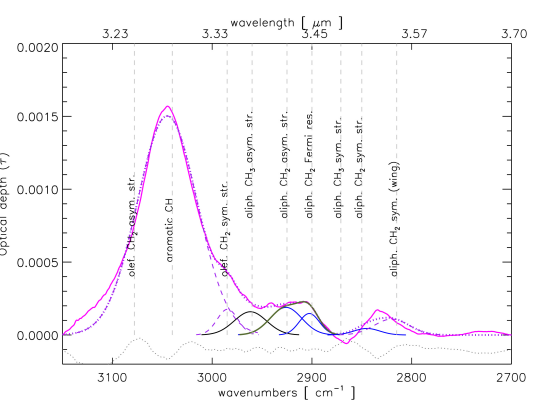

(b) $25 \mathrm{~mm}$

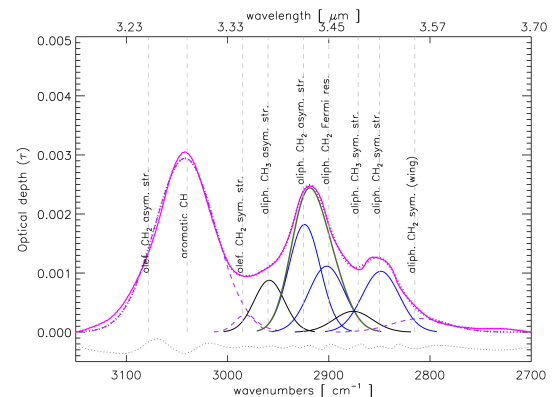

(e) $27 \mathrm{~mm}$

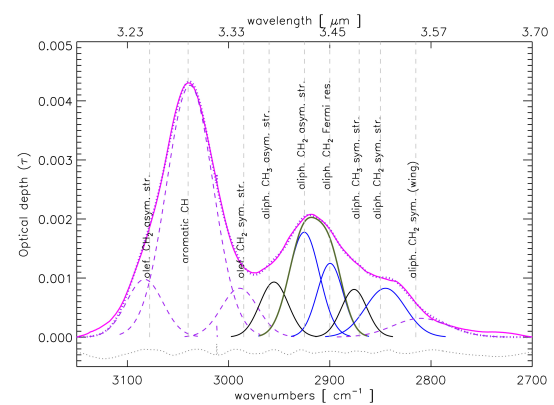

(h) $30 \mathrm{~mm}$

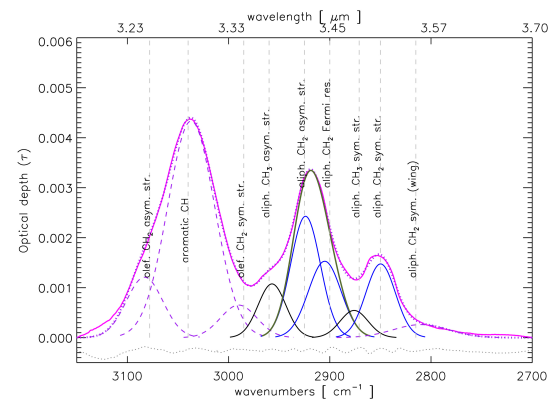

(k) $39 \mathrm{~mm}$

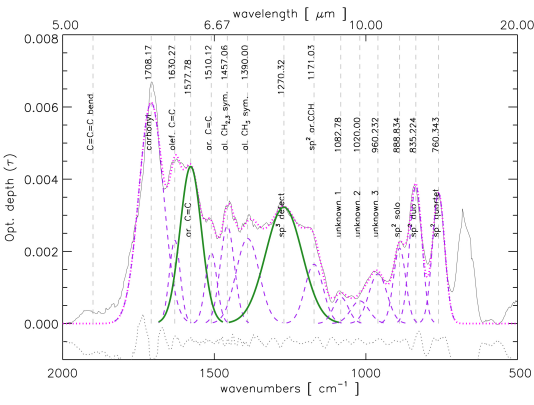

(c) $25 \mathrm{~mm}$

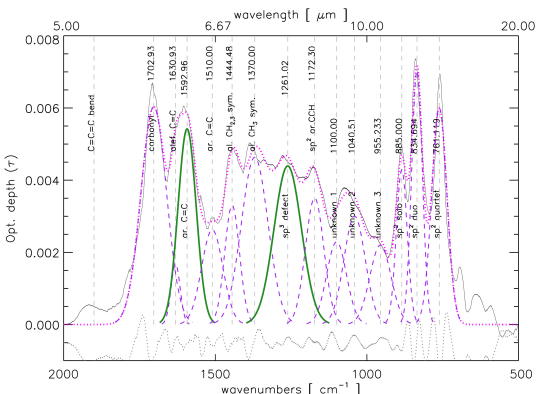

(f) $27 \mathrm{~mm}$

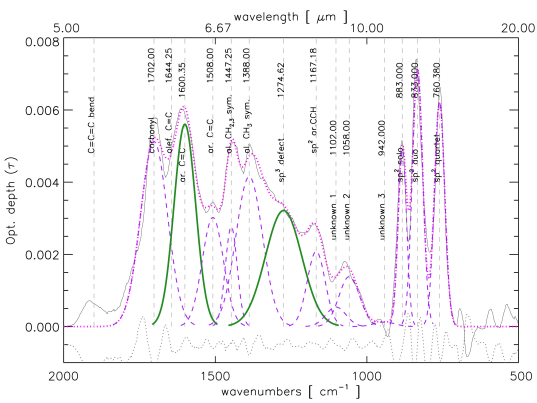

(i) $30 \mathrm{~mm}$

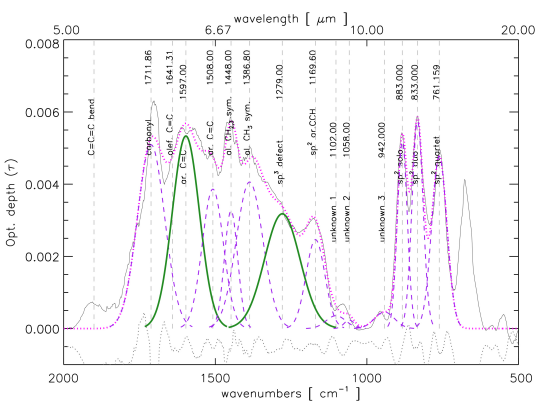

(1) $39 \mathrm{~mm}$

Fig. A.6. UV-VUV and mid-infrared spectral deconvolution for soot samples prepared with a $\mathrm{C} / \mathrm{O}=1.3$ combustion flame, retrieved at a $\mathrm{HAB}$ of a) $25 \mathrm{~mm}$ to $l) 39 \mathrm{~mm}$. 
L. Gavilan et al.: Polyaromatic disordered carbon grains as carriers of the UV bump

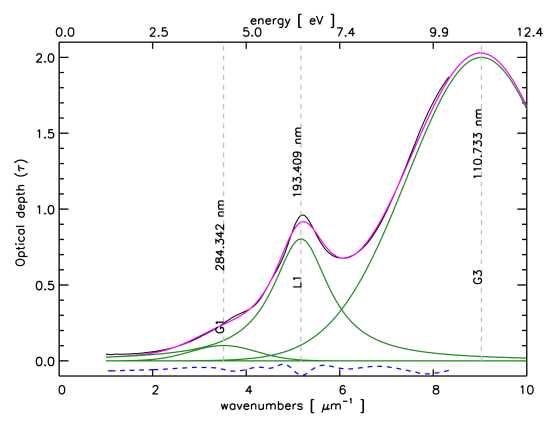

(a) VUV

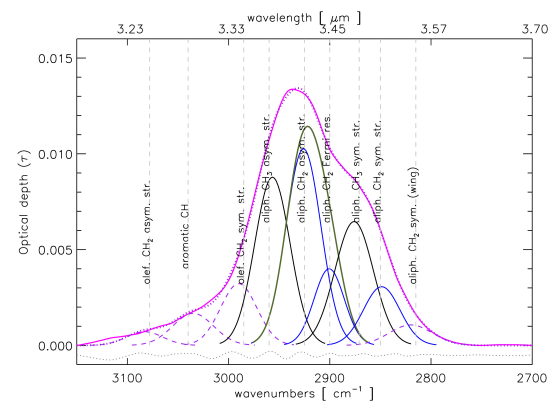

(b) IR

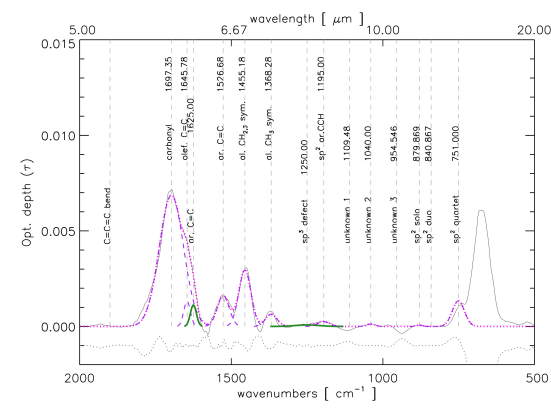

(c) IR

Fig. A.7. UV-VUV and mid-infrared spectral deconvolution for an a-C:H produced with $\mathrm{C}_{7} \mathrm{H}_{8}$. 


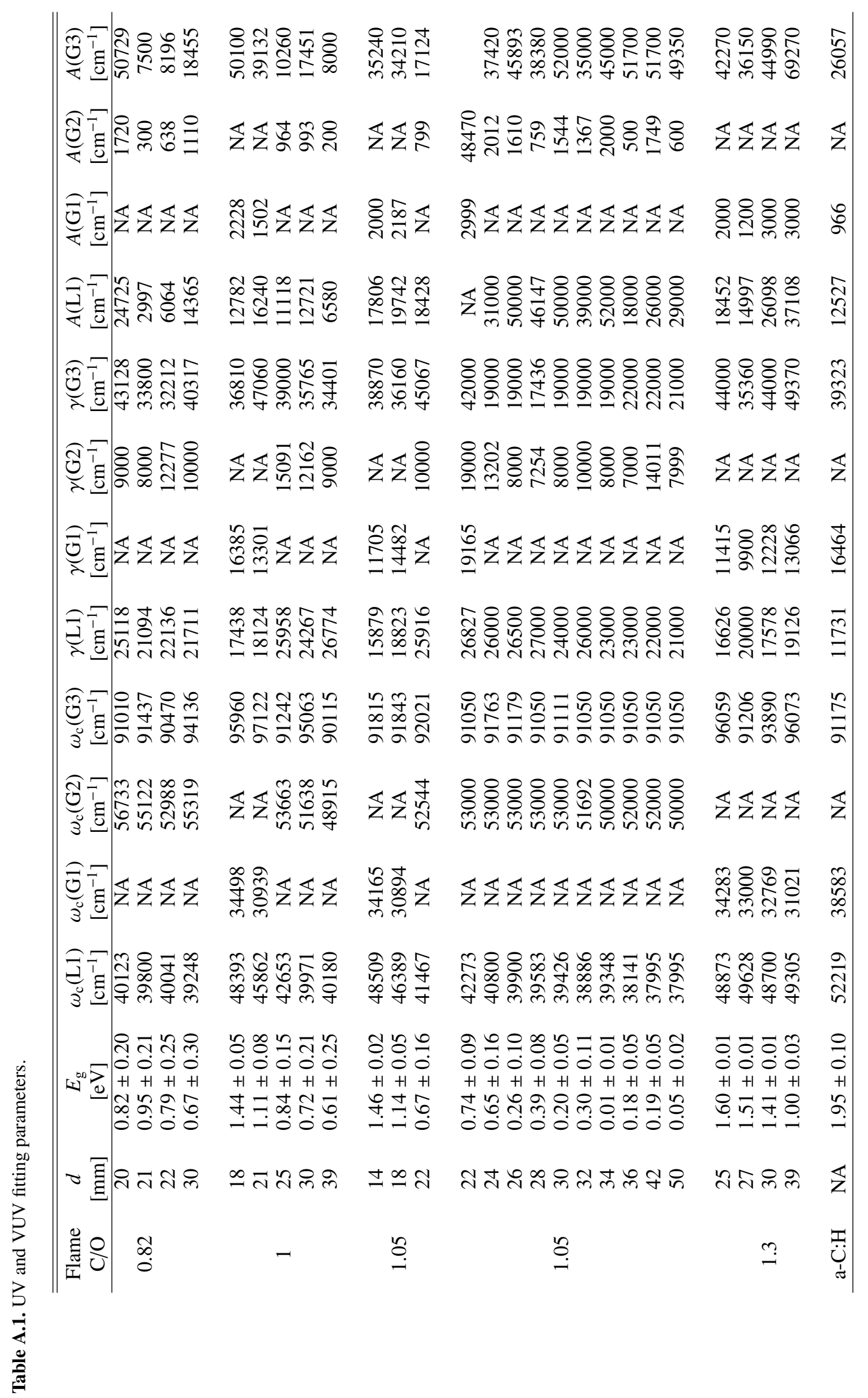




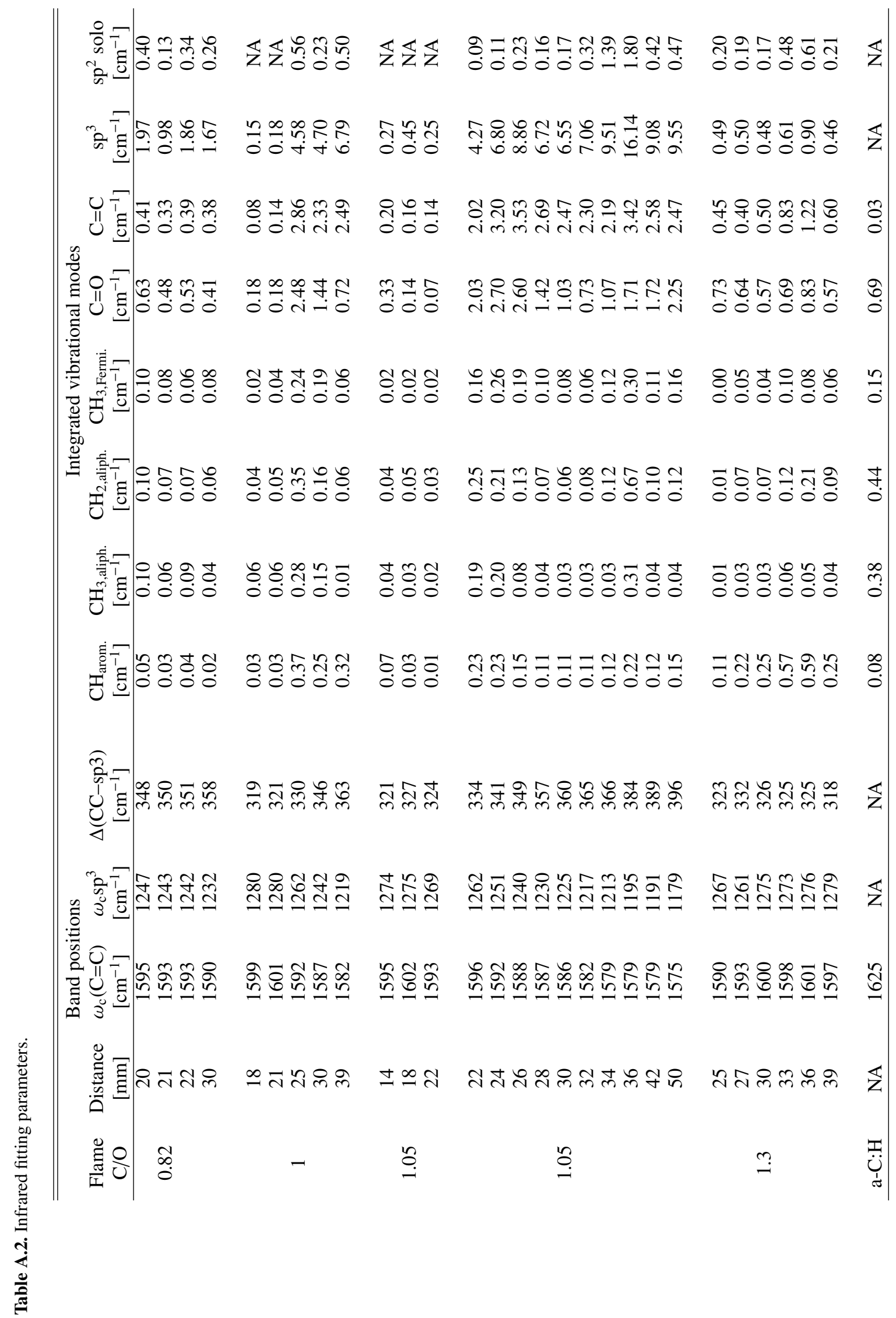

